\title{
Proximal tubule ATR regulates DNA repair to prevent maladaptive renal injury responses
}

\author{
Seiji Kishi, ${ }^{1,2,3,4}$ Craig R. Brooks, ${ }^{1,2,5}$ Kensei Taguchi, ${ }^{5}$ Takaharu Ichimura, ${ }^{1,2}$ Yutaro Mori, ${ }^{1,2}$ Akinwande Akinfolarin, ${ }^{1,2}$ \\ Navin Gupta, ${ }^{1,2,6}$ Pierre Galichon, ${ }^{1,7}$ Bertha C. Elias, ${ }^{5}$ Tomohisa Suzuki, ${ }^{1}$ Qian Wang, ${ }^{1}$ Leslie Gewin, ${ }^{5}$ \\ Ryuji Morizane, ${ }^{1,2,6}$ and Joseph V. Bonventre ${ }^{1,2,6}$
}

'Renal Division, Brigham and Women's Hospital, Boston, Massachusetts, USA. ${ }^{2}$ Department of Medicine, Harvard Medical School, Boston, Massachusetts, USA. ${ }^{3}$ Department of Nephrology, Graduate School of Biomedical Sciences, Tokushima University, Tokushima, Japan. ${ }^{4}$ Department of General Medicine, Kawasaki Medical School, Kurashiki, Japan. ${ }^{5}$ Division of Nephrology and Hypertension, Department of Medicine, Vanderbilt University Medical Center, Nashville, Tennessee, USA. ${ }^{6}$ Harvard Stem Cell Institute, Cambridge, Massachusetts, USA. ``orbonne Université, INSERM UMR S1155, AP-HP, Hôpital Tenon, Paris, France.

\begin{abstract}
Maladaptive proximal tubule (PT) repair has been implicated in kidney fibrosis through induction of cell-cycle arrest at $\mathrm{G}_{2} / \mathrm{M}$. We explored the relative importance of the PT DNA damage response (DDR) in kidney fibrosis by genetically inactivating ataxia telangiectasia and Rad3-related (ATR), which is a sensor and upstream initiator of the DDR. In human chronic kidney disease, ATR expression inversely correlates with DNA damage. ATR was upregulated in approximately $70 \%$ of Lotus tetragonolobus lectin-positive (LTL+) PT cells in cisplatin-exposed human kidney organoids. Inhibition of ATR resulted in greater PT cell injury in organoids and cultured PT cells. PT-specific Atr-knockout (ATR ${ }^{\text {RPTC-I-) }}$ mice exhibited greater kidney function impairment, DNA damage, and fibrosis than did WT mice in response to kidney injury induced by either cisplatin, bilateral ischemia-reperfusion, or unilateral ureteral obstruction. ATR ${ }^{\mathrm{RPTC}-} /-$ mice had more cells in the $\mathrm{G}_{2} / \mathrm{M}$ phase after injury than did WT mice after similar treatments. In conclusion, PT ATR activation is a key component of the DDR, which confers a protective effect mitigating the maladaptive repair and consequent fibrosis that follow kidney injury.
\end{abstract}

\section{Introduction}

Acute kidney injury (AKI) occurs in approximately $13 \%$ of hospitalized patients and is associated with high mortality, especially in critically ill patients (1). AKI also predisposes patients to chronic kidney disease (CKD), which affects approximately $10 \%$ of the world's population (2-4). Renal proximal tubule epithelial cells (RPTECs) comprise the bulk of the renal parenchyma and are the primary targets of a large variety of ischemic and toxic insults $(2,5,6)$. Studies from our laboratory that were also confirmed by others have implicated the DNA damage response (DDR) in the maladaptive repair process after injury $(7,8)$. However, to our knowledge, there have been no studies in which modification of a DDR component in a specific compartment

\section{Related Commentary: p. 4574}

Authorship note: SK and CRB contributed equally to this work. Conflict of interest: JVB and TI are co-inventors on KIM-1 patents (Molecules and methods for inhibiting shedding of KIM-1, patent no. 7696321; Kidney injury-related molecules, patent no. 6664385), which have been assigned to Partners Healthcare and licensed to several companies. JVB and RM are co-inventors on patents (PCT/ US16/52350) on organoid technologies that are assigned to Partners Healthcare. JVB is a consultant to Aldeyra, Angion, Goldilocks, and Medimmune. He is also a consultant to and holds equity in MediBeacon, Sentien Biotech, Thrasos Therapeutics, and Goldfinch Bio and has received grant support from Boehringer Ingelheim. Copyright: () 2019, American Society for Clinical Investigation.

Submitted: June 6, 2018; Accepted: July 23, 2019; Published: October 7, 2019.

Reference information: J Clin Invest. 2019;129(11):4797-4816.

https://doi.org/10.1172/JCl122313. of the kidney has been evaluated for its effect on the long-term response of the kidney to injury.

DNA damage is a feature of many forms of kidney injury (9-12). In response to DNA damage, the cell activates a unique DDR signaling pathway that varies depending on the type of DNA injury. The DDR is activated when 1 or more of the sensor kinases, including ataxia telangiectasia mutated (ATM), ATM- and Rad3-related (ATR), and DNA-dependent protein kinase (DNAPK), detect a DNA strand break. The sensor kinases then activate effectors that upregulate the checkpoint kinases, including checkpoint kinases 1 and 2 (Chk1 and Chk2), which regulate cell-cycle progression through the $G_{1} / S$ or $G_{2} / M$ checkpoint (13-18). In vitro studies suggest that the DDR is cytoprotective against ischemia and ATP depletion (9). Activation of the DDR generally results in DNA repair, but when DNA damage is severe, the ability of the DDR to repair DNA may be overcome. In this case, cells with prolonged DNA damage may enter a state of cell-cycle arrest or undergo apoptosis. We have shown that RPTEC $\mathrm{G}_{2} / \mathrm{M}$ cell-cycle arrest in response to injury results in the generation of proinflammatory and profibrotic cytokines, which promote the development of kidney fibrosis $(7,8)$.

ATR is a phosphoinositide 3-kinase-like kinase that is activated by recognition of single-strand breaks generated after replication fork stalling or as intermediates in nucleotide excision repair and homologous recombination repair. ATR largely acts through the phosphorylation of Chk1 to stop the cell cycle and activate the DDR $(14,19)$. Mutations of the ATR gene in humans have been linked to the development of Seckel syndrome (17), which is characterized 
A

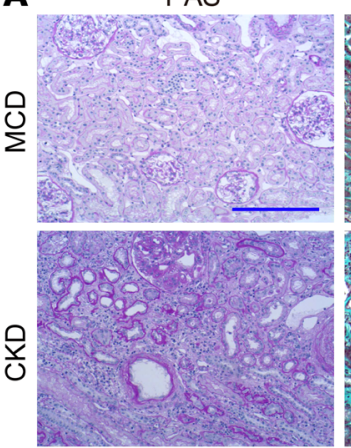

B

CKD
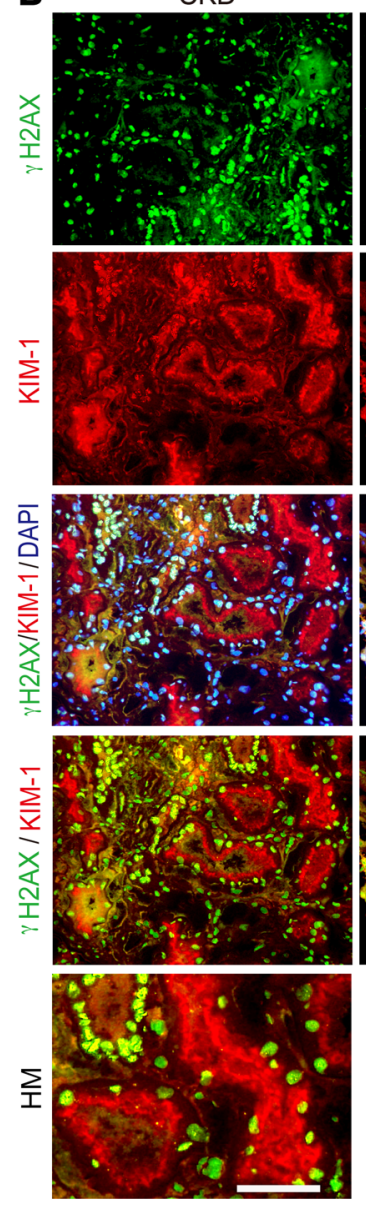

MT

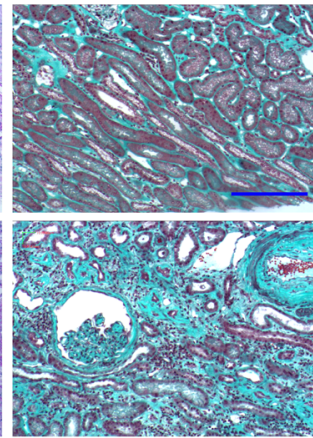

MCD

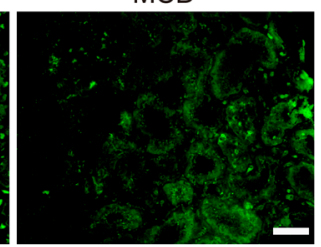

E

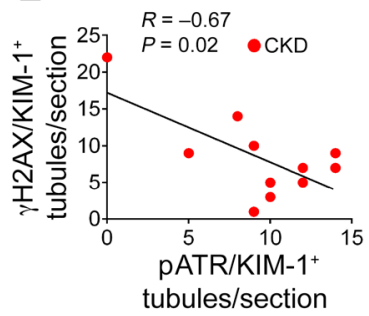

C
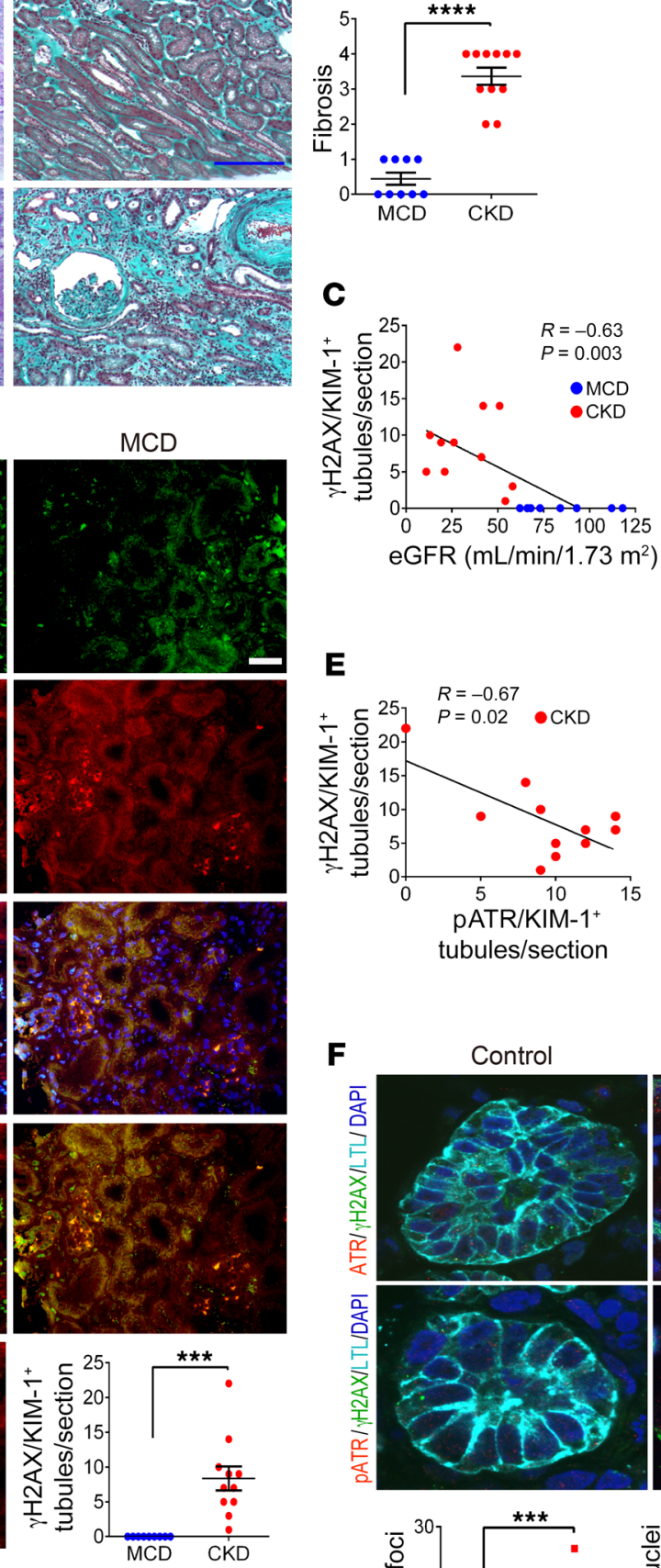

$\mathbf{F}$

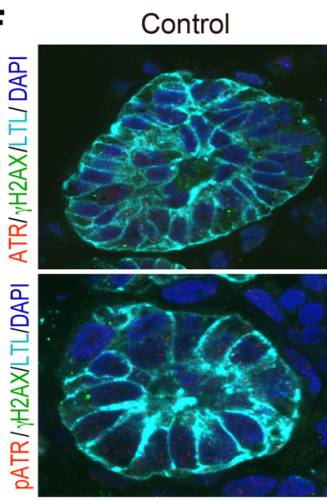

D
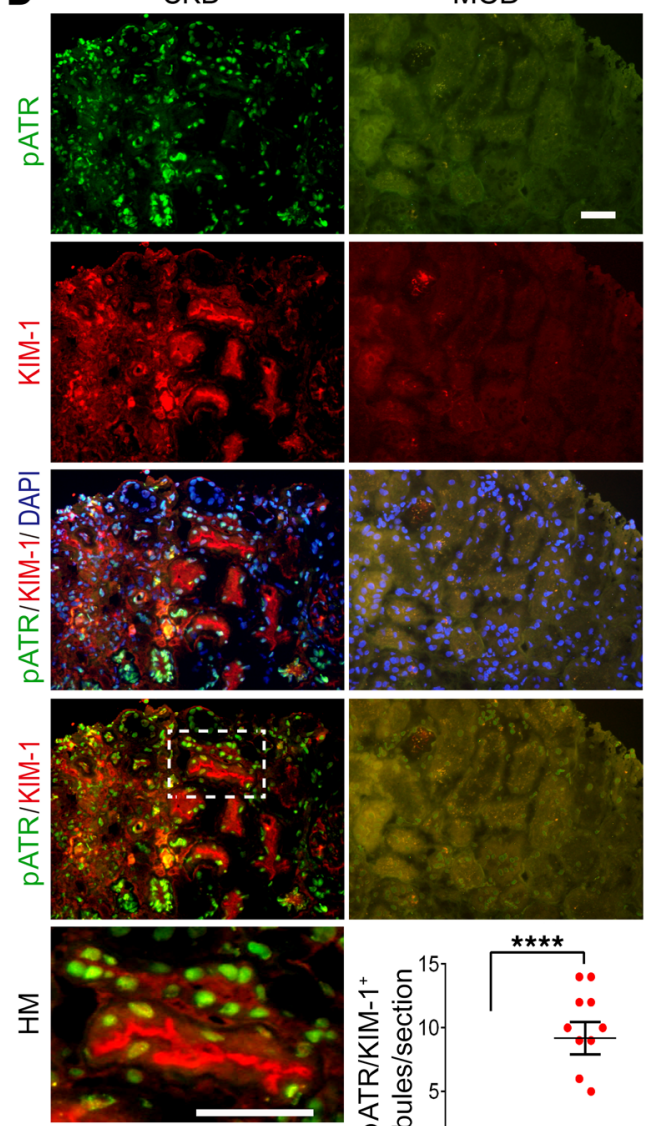

Cisplatin
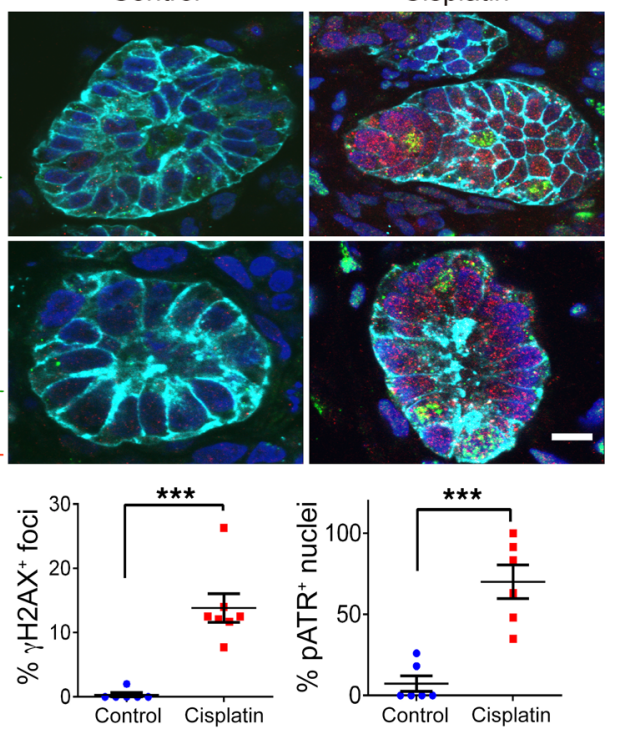
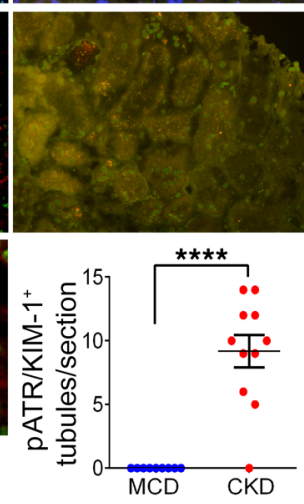

G
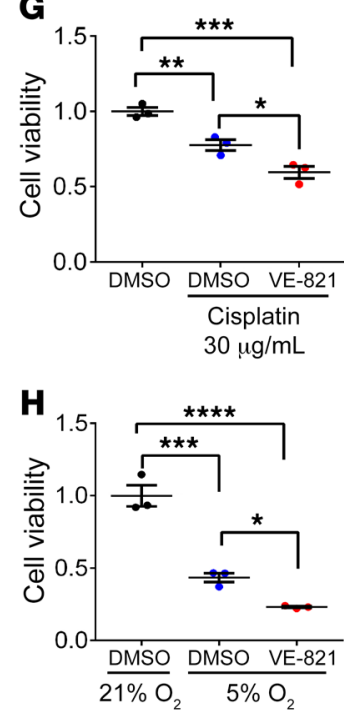
Figure 1. ATR and DNA activation in human kidneys and organoids. (A) Representative images of periodic acid-Schiff (PAS) and MT staining of human kidney tissue and the corresponding quantitation of $\mathrm{MT}^{+}$areas. Scale bars: $10 \mu \mathrm{m}$. (B) Representative images of $\gamma \mathrm{H} 2 \mathrm{AX}$ - and KIM-1-stained sections of human kidneys and the corresponding quantitation of $\gamma \mathrm{H}_{2} \mathrm{AX}^{+} /$ $\mathrm{KIM}-1^{+}$tubules. Scale bars: $10 \mu \mathrm{m}$. (C) Correlation between the number of $\gamma \mathrm{H} 2 \mathrm{AX}+/ \mathrm{KIM}-1^{+}$tubules and eGFR. (D) Representative images of pATRand KIM-1-stained sections of human kidney and the corresponding quantitation of pATR/KIM-1+ tubules. Scale bar: $10 \mu \mathrm{m}$. (E) Relationship between $\gamma \mathrm{H} 2 \mathrm{AX}$ and pATR expression in $\mathrm{KIM}-1^{+}$chronically injured RPTECs. (F) Representative images of $\mathrm{H} 9$ cell-derived day- 49 organoids treated with either cisplatin ( $5 \mu \mathrm{M}$ ) or vehicle (RPMI) for 24 hours. Sections of the organoids were stained for ATR, pATR, $\gamma \mathrm{H} 2 \mathrm{AX}$, and LTL. Scale bar: $20 \mu \mathrm{m}$. Dot plots show quantitation of pATR ${ }^{+}$nuclei ( $n=6$, control; $n=6$, cisplatin) and $\gamma \mathrm{H} 2 \mathrm{AX}+$ nuclei in the organoids ( $n=6$, control; $n=7$, cisplatin). (C) Viability of HKC- 8 cells assessed 24 hours after cisplatin treatment, with or without $10 \mu \mathrm{M}$ VE-821 pretreatment. Viability was determined using the MTT assay. Data are expressed as a percentage of the control MTT value $(n=3)$. (H) Viability of HKC-8 cells was assessed by MTT assay immediately following culturing under $21 \%$ or $5 \% \mathrm{O}_{2}$ for 24 hours, with or without $10 \mu \mathrm{M}$ VE-821 pretreatment. $n=9, \mathrm{MCD} ; n=11, \mathrm{CKD}(\mathbf{A}-\mathbf{E})$. Data are presented as the mean \pm SEM. A 2-tailed, unpaired $t$ test $(\mathbf{A}, \mathbf{B}, \mathbf{D}$, and $\mathbf{F})$, 1-way ANOVA with Tukey's post hoc test ( $\mathbf{G}$ and $\mathbf{H}$ ), and Pearson's correlation analysis (C and $\mathbf{E}$ ) were used to determine statistical significance. ${ }^{*} P<0.05$, ${ }^{* *} P<$ $0.01,{ }^{* *} P<0.001$, and ${ }^{* * * *} P<0.0001$. HM, high-magnification.

by abnormally slow growth during fetal development and postnatally. Studies in mice showed that constitutive deletion of ATR in adulthood leads to increased DNA damage, defects in tissue homeostasis, and the rapid appearance of age-related phenotypes, such as hair-graying, alopecia, kyphosis, osteoporosis, thymic involution, and other abnormalities, similar to what is seen in progeroid (accelerated aging) syndromes in humans (19-21). ATR is activated in RPTECs in vitro and in vivo in response to cisplatin administration (10). Our goal was to better understand the role of ATR in the DDR to injury of RPTECs and its contribution to the maladaptive initiation and progression of interstitial fibrosis $(7,8,22-25)$.

We report that humans with CKD have RPTEC activation of ATR and extensive DNA damage, marked by phosphorylation of the histone $\mathrm{H} 2 \mathrm{~A}$ variant $\mathrm{H} 2 \mathrm{AX}(\gamma \mathrm{H} 2 \mathrm{AX})$, with ATR expression inversely related to the degree of tissue fibrosis. $\gamma \mathrm{H} 2 \mathrm{AX}$ is important for the recruitment and localization of DNA repair proteins (26). ATR and $\gamma \mathrm{H} 2 \mathrm{AX}$ are also markedly upregulated in the RPTECs of kidney organoids derived from human pluripotent stem cells after tubular injury is induced with cisplatin. We hypothesized that reduced RPTEC expression of ATR would result in more cells with unrepaired DNA damage and lead to increased maladaptive repair of the kidney following injury. To test this hypothesis, we specifically deleted the Atr gene from RPTECs in adult mice and then subjected these mice to tubular injury with either bilateral ischemia-reperfusion, cisplatin, or unilateral ureteral obstruction (UUO). We found that the animals with RPTEC deletion of the Atr gene had more cumulative DNA damage, apoptosis, acute impairment of kidney function, and worse kidney fibrosis following ischemia and UUO when compared with littermate controls with intact RPTEC Atr expression. These results were corroborated by in vitro studies of RPTECs and kidney organoids derived from human stem cells. Cumulatively, our findings suggest that after tubular injury, ATR plays an important protective role in RPTECs that leads to less maladaptive repair and kidney fibrosis.

\section{Results}

ATR activation and DNA damage are found in kidney tissue from humans with chronic fibrotic kidney disease and in kidney organoids derived from human stem cells. We analyzed human kidney tissue from 11 subjects with CKD with kidney interstitial fibrosis and elevated serum creatinine concentrations, as well as from 9 individuals with a pathologic diagnosis of minimal change disease (MCD) with normal serum creatinine, good preservation of tubules, and little or no fibrosis (Supplemental Table 1; supplemental material available online with this article; https://doi.org/10.1172/ JCI122313DS1 and Figure 1A). $\gamma \mathrm{H} 2 \mathrm{AX}$ is a sensitive marker for DNA damage $(27,28)$. In kidney tissue from humans with CKD, the number of $\gamma \mathrm{H} 2 \mathrm{AX}$ and KIM-1 double-positive tubules in each kidney section was markedly increased (Figure 1B) and inversely correlated with the estimated glomerular filtration rate (eGFR) (Figure 1C). ATR kinase is activated through phosphorylation and acts as the central regulator of DDR responses through the phosphorylation of ATR substrates, which collectively inhibit DNA replication and mitosis so that the cell can attempt DNA repair, recombination, or, alternatively, undergo apoptosis (29). We detected greater numbers of phosphorylated $\mathrm{ATR}^{+}\left(\mathrm{pATR}^{+}\right)$cells in KIM-1-expressing injured human RPTECs in the kidneys of subjects with CKD (Figure 1D). We noted an inverse correlation between $\gamma \mathrm{H} 2 \mathrm{AX}^{+} / \mathrm{KIM}^{+} 1^{+}$and $\mathrm{pATR}{ }^{+} / \mathrm{KIM}-1^{+}$cells in chronically injured human kidney samples (Figure 1E).

To examine ATR activation in response to toxins in human kidney cells in vitro, we first tested the effects of a nephrotoxin, cisplatin, in human kidney organoids. Cisplatin induces DNA damage by causing inter- and intra-strand crosslinks, leading to replication fork arrest and single-strand breaks in human kidney organoids $(30,31)$. RPTECs are particularly susceptible to injury as a result of increased uptake of cisplatin (32-34), creating cisplatin concentrations in RPTECs that are much higher than in the blood $(35,36)$. Organoids were derived from $\mathrm{H} 9$ human embryonic stem cells (hESCs) via directed differentiation and contained epithelial nephron-like structures that express markers of podocytes, proximal tubules (PTs), loops of Henle, and distal tubules organized in a manner similar to that seen in nephrons in vivo. Importantly, a significant subset of epithelial structures stained with Lotus tetragonolobus lectin (LTL) and with antibodies against aquaporin 1, both markers of differentiated RPTECs. We have previously shown that these cells in the organoids are sensitive to cisplatin treatment and react similarly to RPTECs in vivo $(37,38)$. Staining of frozen sections of cisplatin-treated organoids revealed marked ATR, pATR, and $\gamma \mathrm{H} 2 \mathrm{AX}$ upregulation in nuclei of $\mathrm{LTL}^{+}$RPTECs (Figure 1F).

Next, we tested the effect of ATR inhibition on cultured RPTECs. We found that HKC-8 cell viability was decreased with $30 \mu \mathrm{g} / \mathrm{mL}$ cisplatin treatment in vitro and that pretreatment with the ATR inhibitor VE-821 $(10 \mu \mathrm{M})$ resulted in a further reduction in cell viability after cisplatin exposure (Figure $1 G$ ). In addition, cell viability was reduced in DMSO-treated HKC-8 cells when cells were exposed to reduced oxygen tension (5\%) for 24 hours, and this effect was further exacerbated in the presence of VE-821 (Figure 1H). Thus, DNA damage and activation of the DDR are prominent features of RPTECs in human tissue with chronic injury in vivo (CKD) and in vitro in both human organoids and human cells in culture undergoing toxin- or hypoxia-induced cell injury. 

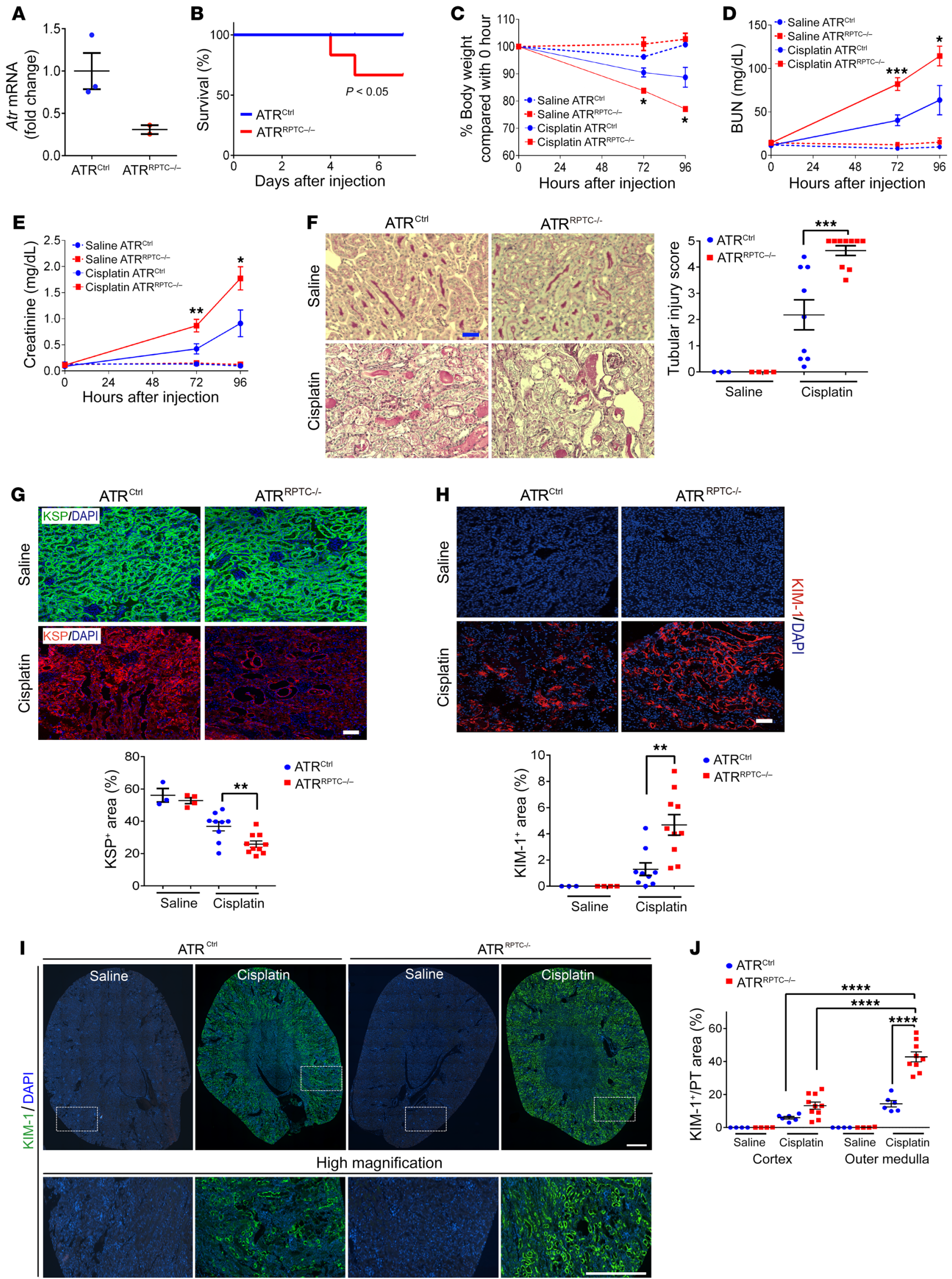
Figure 2. PT Atr gene deletion exacerbates cisplatin-induced AKI. (A) Real-time PCR analysis of Atr mRNA levels in ATR ${ }^{\mathrm{Ctrl}}$ and $\mathrm{ATR}^{\mathrm{RPTC}-\mathrm{I}_{-}}$kidneys 96 hours after cisplatin administration. $\operatorname{ATR}^{\mathrm{Ctrl}}(n=3)$; $\operatorname{ATR}^{\mathrm{RPTC}-/-}(n=$ 2). (B) Survival after cisplatin injection was monitored until day 7. ATR ${ }^{\mathrm{Ctrl}}$ $(n=18)$, ATR RPTC-I- $(n=18)$. (C) Body weight (vs. O hour), (D) BUN, and (E) serum creatinine levels over time, 72 and 96 hours after saline or cisplatin administration. Saline (72 h): $\operatorname{ATR}^{\mathrm{Ctrl}}(n=3)$, $\operatorname{ATR}^{\mathrm{RPTC}-1-}(n=4)$; cisplatin (72 h): $\operatorname{ATR}^{\text {ctrl }}(n=18), \operatorname{ATR}^{\text {RPTC- }-}(n=18)$. Saline (96 h): $\operatorname{ATR}^{\text {trrl }}(n=3), \operatorname{ATR}^{\text {RPTC- }-}$ $(n=4)$; cisplatin $(96 \mathrm{~h})$ : $\operatorname{ATR}^{\mathrm{Ctrl}}(n=9), \operatorname{ATR}^{\mathrm{RPTC}-/-}(n=10)$. (F) Representative kidney histology as shown by PAS staining 96 hours after saline or cisplatin injection. Scale bar: $50 \mu \mathrm{m}$. Dot plot shows the corresponding quantification of tubular injury score. Saline: $\operatorname{ATR}^{\mathrm{Ctrl}}(n=3)$, $\operatorname{ATR}^{\mathrm{RPTC}-{ }_{-}-}(n=4)$; cisplatin: $\operatorname{ATR}^{\mathrm{Ctrl}}(n=9)$, ATR ${ }^{\mathrm{RPTC}-I-}(n=10)$. (G) Representative images of KSP-stained sections of injured kidneys from ATR ${ }^{\mathrm{ctrl}}$ and $\mathrm{ATR}^{\mathrm{RPTC}-/-}$ mice 96 hours after cisplatin injection. Scale bar: $50 \mu \mathrm{m}$. Dot plot shows the corresponding quantification of $\mathrm{KSP}^{+}$areas. Saline: $\operatorname{ATR}^{\mathrm{Ctr}}(n=3)$, $\operatorname{ATR}^{\mathrm{RPTC}-{ }_{-}}(n=4)$; cisplatin: $\operatorname{ATR}^{\text {Ctrl }}(n=9)$, ATR RPT- RT- $^{2}(n=10)$. (H) Representative images of KIM-1-

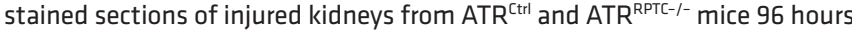
after cisplatin injection. Scale bar: $50 \mu \mathrm{m}$. Dot plots shows the corresponding quantification of KIM-1 $1^{+}$areas. Saline: $\operatorname{ATR}^{\mathrm{Ctrl}}(n=3), \operatorname{ATR}^{\mathrm{RPTC}-\text { I- }^{-}}(n=4)$; cisplatin: $\operatorname{ATR}^{\mathrm{Ctrl}}(n=9)$, ATR ${ }^{\mathrm{RPTC}-/-}(n=10)$. (I) Coimmunostaining for KIM-1

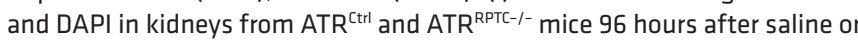
cisplatin injection. Top panels: Stitched images of whole kidney cross-sectional area (original magnification, $\times 200$ ). Bottom panels: Higher-magnification images from the boxed regions in the stitched images. Scale bars: $500 \mu \mathrm{m}$. (J) Quantification of KIM-1 staining in cortex or outer medulla from whole kidney section images in I, normalized to control LTL staining. Saline: $\operatorname{ATR}^{\mathrm{Ctrl}}(n=4)$, $\operatorname{ATR}^{\mathrm{RPTC}-I-}(n=4)$; cisplatin: $\operatorname{ATR}^{\mathrm{Ctrl}}(n=6)$, $\operatorname{ATR}^{\mathrm{RPTC}-I_{-}}$ $(n=10)$. Data are presented as the mean \pm SEM. Kaplan-Meier method with comparison using the log-rank test (B), a 2-tailed, unpaired $t$ test

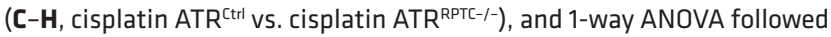
by Tukey's post hoc test (J) were used to determine statistical significance. ${ }^{*} P<0.05,{ }^{* *} P<0.01$, and ${ }^{* * *} P<0.001$, ${ }^{* * *} P<0.0001$.

PT Atr gene deletion exacerbates cisplatin-induced AKI. To evaluate whether ATR plays a role in cisplatin-induced RPTEC injury in vivo, we depleted the Atr gene specifically from mouse RPTECs. Atr conditional-knockout mice were generated by crossing Atr ${ }^{f / f l}$ mice with Atr heterozygous Slc34a1-GFPCreERT ${ }^{2}$ $\left(A t r^{+/-}\right.$Slc34a1 $\left.{ }^{G C E /+}\right)$ mice $(19,39)$. The resulting Atr ${ }^{f /-} S l c 34 a 1^{G C E /+}$ mice were bred together to generate Atr $\mathrm{fl}^{\mathrm{f} / \mathrm{S}} \mathrm{Slc} 34 a 1^{\mathrm{GCE} /+}$ or $A t r^{\mathrm{fl} / \mathrm{fl}}$ Slc34a1 ${ }^{G C E /+}$ mice, in which Atr was deleted in a tamoxifendependent manner (ATR $\left.{ }^{\mathrm{RPTC}-} /-\right)$. These mice were compared with littermate controls, which carried the ATR-floxed allele but did not carry the Cre transgene (ATR $\left.{ }^{\mathrm{Ctrl}}\right)(19,39)$. We confirmed decreased total kidney Atr mRNA by quantitative real-time PCR (qPCR) in the $\mathrm{ATR}^{\mathrm{RPTC}-/-}$ mice 96 hours after cisplatin injection (Figure 2A). Kaplan-Meier survival analysis demonstrated that cisplatin administration (20 mg/kg i.p.) to $\mathrm{ATR}^{\mathrm{RPTC}-/-}$ mice led to significantly increased mortality by day 7 when compared with $\mathrm{ATR}^{\mathrm{C} \text { trl }}$ mice (Figure 2B). In addition, although there were no significant differences in body weight between $\mathrm{ATR}^{\mathrm{RPTC}-/-}$ and $\mathrm{ATR}^{\mathrm{Ctrl}}$ mice after saline vehicle treatment, following cisplatin treatment, $\mathrm{ATR}^{\mathrm{RPTC}-/-}$ mice lost significantly more weight when compared with their ATR ${ }^{\text {Ctrl }}$ littermates (Figure $2 \mathrm{C}$ ). Serum creatinine and blood urea nitrogen (BUN) levels in response to cisplatin-induced tubular injury were significantly higher in $\mathrm{ATR}^{\mathrm{RPTC}-/-}$ mice compared with levels in ATR ${ }^{\mathrm{Ctrl}}$ mice (Figure 2, D and E). Consistent with greater kidney dysfunction, ATR $^{\mathrm{RPTC}-/-}$ mice had higher tubular injury scores (composite of necrotic tubules, cast formation, and dilated tubules) when compared with scores for $\mathrm{ATR}^{\mathrm{Ctrl}}$ mice
96 hours after cisplatin injection (Figure 2F). Ninety-six hours after cisplatin injection, kidney cortex kidney-specific proteinpositive $\left(\mathrm{KSP}^{+}\right)$areas (KSP is expressed in all tubular segments in mice; refs. 40-42) in $\mathrm{ATR}^{\mathrm{RPTC}-/-}$ mice were significantly reduced (Figure $2 \mathrm{G}$ ), and KIM-1 staining was significantly greater (Figure $2 \mathrm{H})$ in $\mathrm{ATR}^{\mathrm{RPTC}-/-}$ mice compared with that seen in $\mathrm{ATR}^{\mathrm{Ctrl}}$ mice. KIM-1 expression was higher in the outer medulla than in the cortex in both $\mathrm{ATR}^{\mathrm{Ctrl}}$ and $\mathrm{ATR}^{\mathrm{RPTC}-/-}$ mice; however, $\mathrm{ATR}^{\mathrm{RPTC}-/-}$ mice had higher expression of KIM-1 in both regions than did ATR ${ }^{\mathrm{Ctrl}}$ mice (Figure 2, I and J). This observation is consistent with previous reports that the $\mathrm{S} 3$ segment of the PT is most sensitive to cisplatin injury (43). Thus, RPTEC Atr gene depletion results in enhanced cisplatin-induced RPTEC injury 96 hours after treatment.

Atr gene deletion in RPTECs enhances DNA damage and leads to more apoptosis after cisplatin injection. $\gamma \mathrm{H} 2 \mathrm{AX}$ localizes to the sites of DNA single-strand breaks and functions to recruit replication protein A (RPA) and ATR to sites of DNA damage $(44,45)$. The nucleus-wide $\gamma \mathrm{H} 2 \mathrm{AX}$ response represents an apoptotic signal that is mediated by $\mathrm{p} 53$ and pan-caspases $(45,46)$. Nucleus-wide $\gamma \mathrm{H}_{2} \mathrm{AX}^{+}$and $\gamma \mathrm{H} 2 \mathrm{AX}^{+}$foci were quantitated separately to evaluate the relationship between ATR, DNA damage, and apoptosis in more detail. We detected significantly increased numbers of total $\gamma \mathrm{H} 2 \mathrm{AX}$-labeled RPTECs (nucleus-wide and foci) after cisplatin injury in $\mathrm{ATR}^{\mathrm{RPTC}-/-}$ mice when compared with numbers in ATR $^{\text {Ctrl }}$ mice, 96 hours after cisplatin administration (Figure $3 \mathrm{~A})$. The number of $\gamma \mathrm{H} 2 \mathrm{AX}^{+}$foci was significantly increased in $\mathrm{ATR}^{\mathrm{RPTC}-{ }^{-}}$mice, whereas the number of nucleus-wide $\gamma \mathrm{H} 2 \mathrm{AX}^{+}$ cells trended toward an increase (Figure $3 \mathrm{~A}$ ). The outer medulla had a higher concentration of $\gamma \mathrm{H} 2 \mathrm{AX}^{+}$cells compared with the cortex, again suggesting that this region had the most injury (Figure $3 \mathrm{~A})$. In addition, we found that RPTECs had increased labeling for cleaved caspase 3 staining in $\mathrm{ATR}^{\mathrm{RPTC}-/-}$ mice when compared with ATR $^{\text {Ctrl }}$ mice (Figure $3 \mathrm{~B}$ ). Caspase 3 activation was higher in the outer medulla than in the cortex in $\mathrm{ATR}^{\mathrm{Ctrl}}$ mice, whereas $\mathrm{ATR}^{\mathrm{RPTC}-1-}$ mice showed increased caspase 3 activation in both regions of the kidney, with a greater increase in the outer medulla (Figure 3C). Ninety-six hours after cisplatin exposure, we observed no difference in the number of $\mathrm{Ki}^{+} 7^{+}$tubular or interstitial cells between $\mathrm{ATR}^{\mathrm{Ctrl}}$ and $\mathrm{ATR}^{\mathrm{RPTC}-/-}$ mice (Figure 3D). As shown in Figure $3 \mathrm{E}$, the majority of the $\mathrm{Ki} 67^{+}$cells did not stain for $\mathrm{F} 4 / 80$ or $\alpha$-smooth muscle actin ( $\alpha$-SMA), indicating that the majority of cells were tubular cells and not macrophages or myofibroblasts.

Ninety-six hours following cisplatin injection, we evaluated the p53/p21 signaling pathway, an effector pathway of the DDR that is downstream of ATR and known to initiate $G_{2} / \mathrm{M}$ cell-cycle arrest. We detected higher p53 protein expression in $\mathrm{ATR}^{\mathrm{RPTC}-/-}$ mice than in $\mathrm{ATR}^{\mathrm{Ctrl}}$ mice. This increase in p53 in the absence of adequate ATR-mediated DNA repair could have activated $G_{1} / S$ and/or $\mathrm{G}_{2} / \mathrm{M}$ cell-cycle checkpoints in the $\mathrm{ATR}^{\mathrm{RPTC}-/-}$ mice. mRNA and protein levels of $\mathrm{p} 21$, a transcriptional target of $\mathrm{p} 53$, were also significantly higher in $\mathrm{ATR}^{\mathrm{RPTC}-/-}$ mice (Figure $3 \mathrm{~F}$ ). $\mathrm{ATR}^{\mathrm{RPTC}-/-}$ mice had greater numbers of RPTECs that stained positive for phosphorylated histone $\mathrm{H} 3(\mathrm{pH} 3)$ at Ser10, indicating that more RPTECs were in the $G_{2} / M$ phase of the cell cycle (Figure $4 A$ ). $\mathrm{ATR}^{\mathrm{RPTC}-1-}$ mice tended to have more $\mathrm{F} 4 / 80$-labeled interstitial macrophages than did $\mathrm{ATR}^{\mathrm{Ctrl}}$ animals, but the difference was not statistically significant (Figure $4 \mathrm{~B}$ ). 

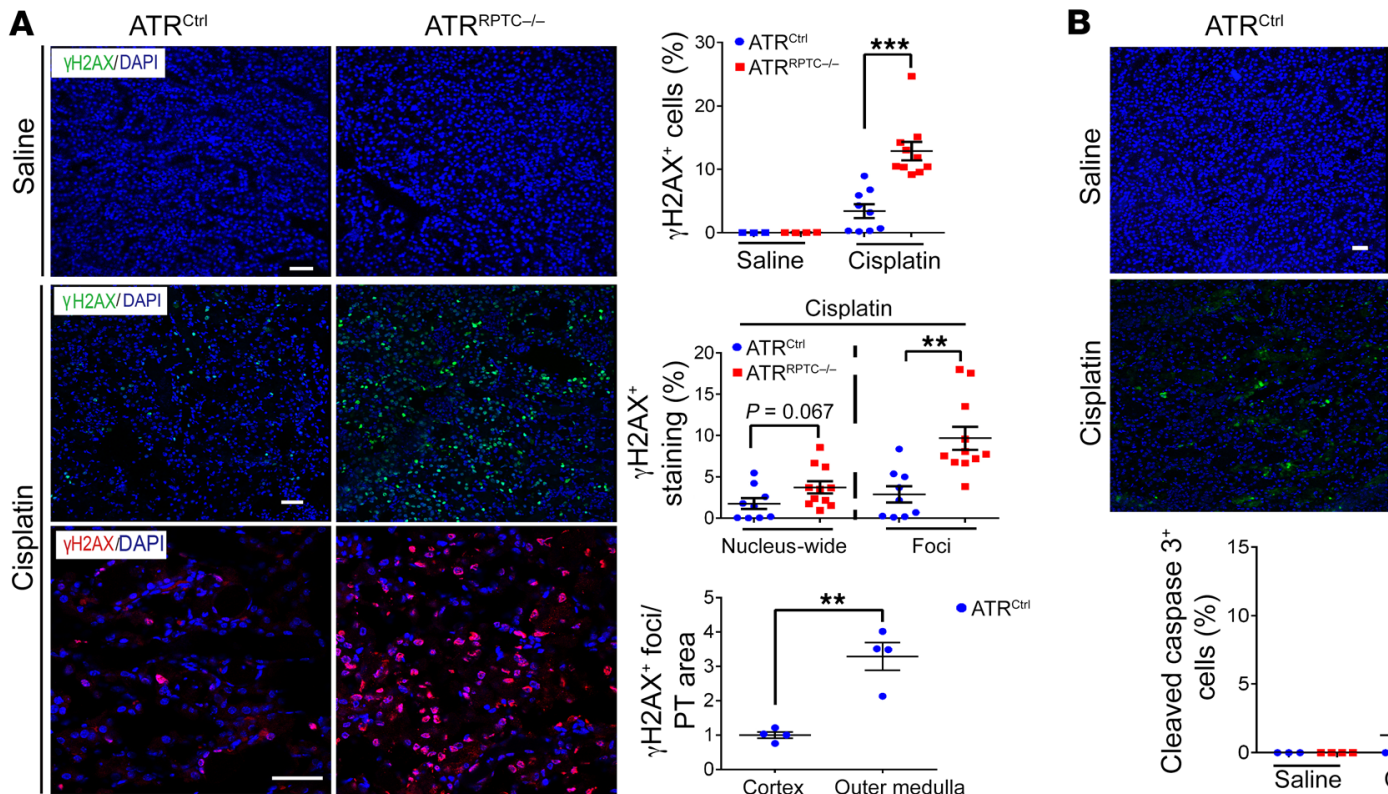

ATR RPTC-I-
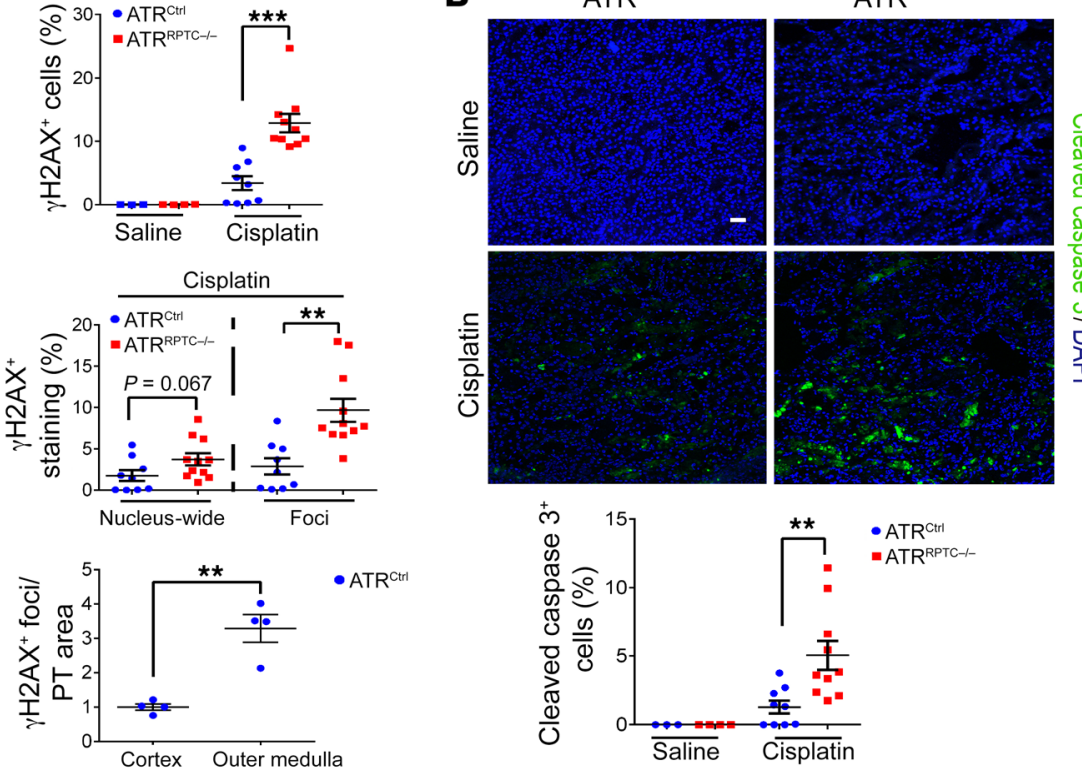

C

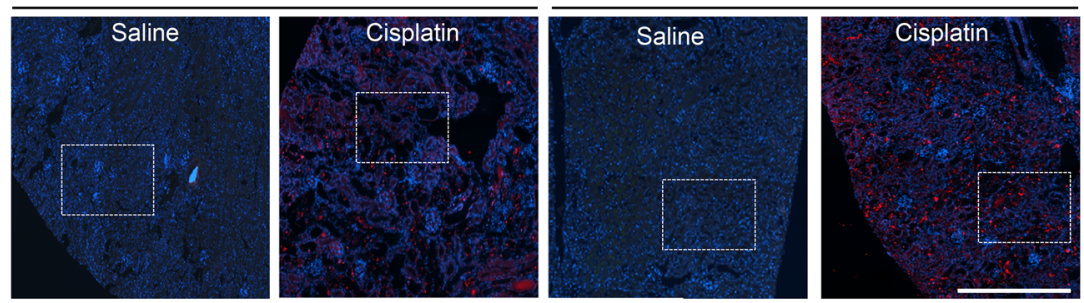

High magnification
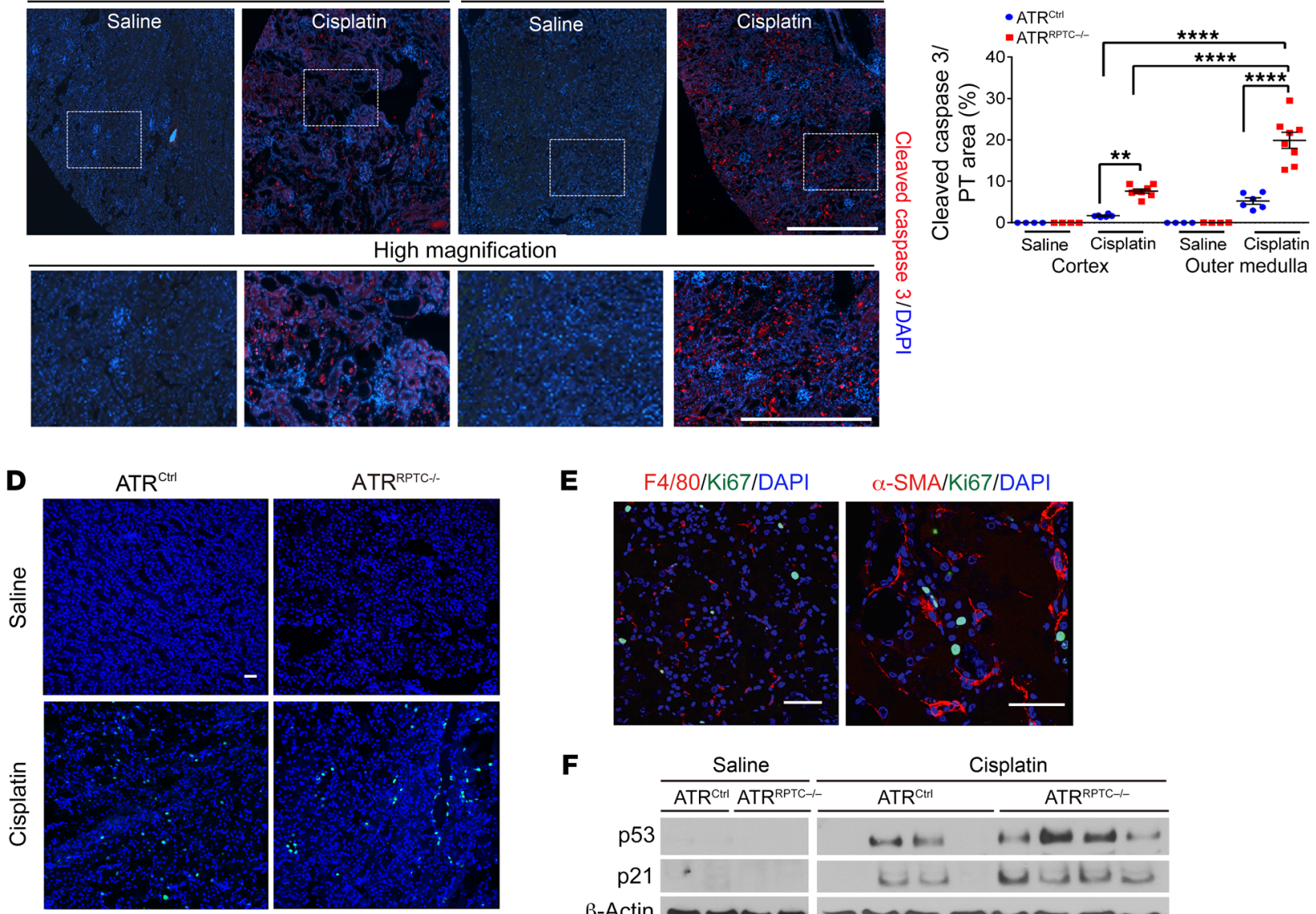

E

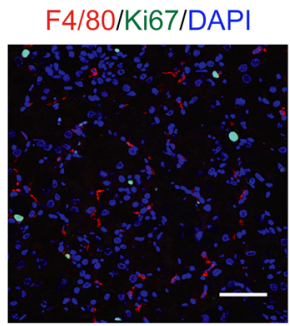

$\alpha$-SMA/Ki67/DAPI

Ki67/DAPI

F

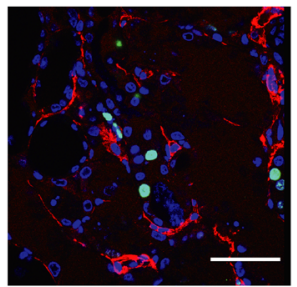

\begin{tabular}{|c|c|c|c|}
\hline & Saline & & splatin \\
\hline & $\mathrm{ATR}^{\mathrm{Ctrl}} \mathrm{ATR}^{\mathrm{RPTC}-1}$ & $\mathrm{ATR}^{\mathrm{Ctrl}}$ & ATR RPTC-1- \\
\hline p53 & & $\cdots+4$ & $+\ldots$ \\
\hline p21 & - & $\cos$ & UULU \\
\hline ctin & $\rightarrow-\infty$ & $-\infty$ & $\rightarrow \infty$ \\
\hline
\end{tabular}
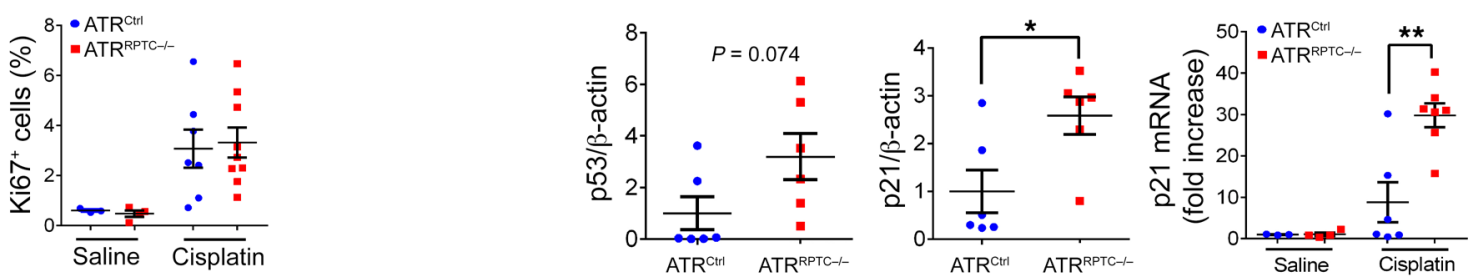
Figure 3. ATR ${ }^{\mathrm{RPTC}-/-}$ mice have enhanced DNA damage and apoptosis after cisplatin injection. (A) Representative images of $\gamma \mathrm{H} 2 \mathrm{AX}$-stained

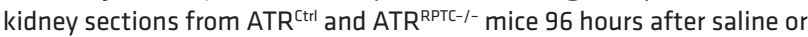
cisplatin injection. Scale bars: $50 \mu \mathrm{m}$. Dot plots show quantification of $\gamma \mathrm{H}_{2} \mathrm{AX} \mathrm{X}^{+}$cells, percentage of cells with nucleus-wide $\gamma \mathrm{H} 2 \mathrm{AX} \mathrm{X}^{+}$staining or $\gamma \mathrm{H}_{2} \mathrm{AX}^{+}$foci, and $\gamma \mathrm{H} 2 \mathrm{AX} X^{+}$cells in cortex versus outer medulla. Saline: $\operatorname{ATR}^{\mathrm{Ctrl}}(n=3)$, ATR ${ }^{\mathrm{RPTC}-I^{-}}(n=4)$; cisplatin: $\operatorname{ATR}^{\mathrm{Ctrl}}(n=9), \operatorname{ATR}^{\mathrm{RPTC}-/-}(n=11)$. (B) Representative images of cleaved caspase 3-stained kidney sections from ATR $^{\mathrm{Ctrl}}$ and $\mathrm{ATR}^{\mathrm{RPTC}-/-}$ mice 96 hours after saline or cisplatin injection. Scale bar: $50 \mu \mathrm{m}$. Dot plot shows corresponding quantification of cleaved caspase $3^{+}$cells. Saline: ATR ${ }^{\mathrm{Ctrl}}(n=3)$, ATR ${ }^{\mathrm{RPTC}-{ }_{-}-(}(n=4)$; cisplatin: $\operatorname{ATR}^{\mathrm{Ctrl}}$ $(n=9)$, ATR ${ }^{\text {RPTC-I- }}(n=11)$. (C) Immunostaining for cleaved caspase 3 and

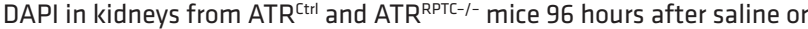
cisplatin injection. Upper panels: Stitched images represent approximately $25 \%$ of the kidney cross-sectional area (original magnification, $\times 200$ ). Lower panels: Higher-magnification images from the boxed regions in the stitched (upper) images (scale bar: $500 \mu \mathrm{m}$ ). Dot plot shows quantification of cleaved caspase 3 staining from the whole kidney section images in $\mathbf{C}$ relative to the $\mathrm{LTL}^{+}$area of uninjured kidney tissue. Saline: $\operatorname{ATR}^{\mathrm{Ctrl}}(n=4), \operatorname{ATR}^{\mathrm{RPTC}-/-}(n=4)$; cisplatin: $\operatorname{ATR}^{\mathrm{Ctrl}}(n=6), \operatorname{ATR}^{\mathrm{RPTC}-I_{-}}(n=8)$. (D) Representative images of Ki67-stained kidney sections from ATR ${ }^{\mathrm{Ctrl}}$ and ATR ${ }^{\text {RPTC- }- \text { - mice }} 96$ hours after saline or cisplatin injection. Scale bar: $50 \mu \mathrm{m}$. Dot plot shows corresponding quantification of Ki67+ cells. Saline: $\operatorname{ATR}^{\mathrm{Ctrl}}(n=3), \operatorname{ATR}^{\mathrm{RPTC}-/-}(n=4)$; cisplatin: $\operatorname{ATR}^{\mathrm{Ctrl}}(n=7), \operatorname{ATR}^{\mathrm{RPTC}-1-}(n=9)$. (E) Representative images of F4/80- and Ki67-stained and $\alpha$-SMA- and Ki67-stained sections of injured kidneys from ATR ${ }^{\text {RTTC-I- }}$ mice 96 hours after cisplatin injection. Scale bar: $50 \mu \mathrm{m}$. (F) Representative Western blot. Each lane represents 1 sample from an individual mouse. Dot plots show quantification of Western blot band intensity for $p 53$ and p21, 96 hours after cisplatin injection. $\operatorname{ATR}^{\mathrm{Ctrl}}(n=6), \operatorname{ATR}^{\mathrm{RPTC}-/-}(n=6)$. Also shown is a dot plot of quantitative RT-PCR analysis of p21 mRNA levels in ATR ${ }^{\mathrm{Ctrl}}$ and

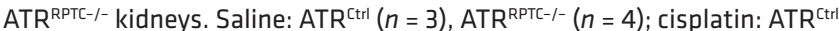
$(n=6), \operatorname{ATR}^{\text {RPTC-I- }}(n=7)$. Data are presented as the mean \pm SEM. Statistical significance was determined by 2-tailed, unpaired $t$ test (A, B, D, and $\mathbf{F}$, for cisplatin ATR ${ }^{\text {ctrl }}$ vs. cisplatin ATR ${ }^{\text {RPTC- }- \text { - }}$ ) and 1-way ANOVA followed by Tukey's post-hoc test (C). ${ }^{*} P<0.05,{ }^{* *} P<0.01$, ${ }^{* * *} P<0.001$, and ${ }^{* * *} P<$ 0.0001 . See the complete unedited blots in the supplemental material.

We complemented the in vivo experiments with studies in cultured mouse RPTECs, pig kidney LLC-PK1 cells, and human kidney organoids. RPTECs and LLC-PK1 cells treated with cisplatin plus the ATR inhibitor VE-821 had significantly higher caspase 3 activation compared with cisplatin treatment alone (Figure 4, C and D). Next, we tested the effect of ATR inhibition on cisplatin-induced injury in human kidney organoids. Organoids treated with cisplatin plus VE-821 had a significant reduction in the number of $\mathrm{LTL}^{+}$tubules and an increased percentage of $\mathrm{LTL}^{+}$ cells double-positive for $\mathrm{pH} 3$ and Ki67 (Figure 4, E-G). These data demonstrate that deletion of ATR in RPTECs, LLC-PK1 cells, and human kidney organoids significantly worsens cisplatin-induced kidney injury and increases the number of cells in the $G_{2} / M$ phase of the cell cycle.

Atr gene deletion promotes $G_{2} / M$ arrest in cisplatin-injured RPTECs. The results in Figure 4A suggest that there was an accumulation of cell-cycle-arrested RPTECs following injury in the $\mathrm{ATR}^{\mathrm{RPTC}-/}$ mice. To determine whether RPTECs were arrested in $\mathrm{G}_{1} / \mathrm{S}$ or $\mathrm{G}_{2} / \mathrm{M}$, the cell cycle was analyzed using the fluorescence ubiquitination-based cell-cycle indicator (FUCCI) (47). In primary RPTECs isolated from FUCCI2a mice, cisplatin treatment resulted in a marked increase in $\mathrm{G}_{1}$ - and a reduction in $\mathrm{S} / \mathrm{G}_{2} / \mathrm{M}$-phase cells, suggesting activation of the $G_{1} / S$ checkpoint. When the ATR inhibitor VE-821 was added with cisplatin, we observed a marked increase in $S / G_{2} / M$-phase cells (Figure $5 A$ ). Live microscopy cell-cycle assessment of HK-2 cells expressing FUCCI revealed that inhibition of $\mathrm{p} 53$ by pifithrin- $\alpha$ resulted in an increase in mKO$\mathrm{Cdt}^{+} \mathrm{G}_{1}$-phase cells, with a corresponding decrease in MAG-gem$\operatorname{inin} S / G_{2}$-phase cells. By comparison, incubation with rigosertib, $a_{G_{2}} / M$ arrest inducer, increased the number of cells in the $G_{2} / M$ phase of the cell cycle (Figure 5, B and C). After establishment in primary culture, under basal conditions, we noted increased numbers of primary RPTECs from $\mathrm{ATR}^{\mathrm{RPTC}-/}$ mice in $\mathrm{G}_{2} / \mathrm{M}^{\mathrm{Rela}-}$ tive to cells from WT mice, indicating an increased sensitivity of $\mathrm{ATR}^{\mathrm{RPTC}-/}$ cells to the stresses of isolation and culture, activating the $\mathrm{G}_{2} / \mathrm{M}$ checkpoint (Figure 5, D-F). These findings indicated that ATR inhibition leads to increased $\mathrm{G}_{2} / \mathrm{M}$ cell-cycle arrest, which our laboratory and others have linked to maladaptive repair and fibrosis, and that p53 inhibition reduces $\mathrm{G}_{2} / \mathrm{M}$ arrest.

Atr gene depletion in RPTECs results in increased profibrotic changes after ischemia-reperfusion injury. ATR is upregulated following bilateral ischemia-reperfusion injury (IRI) in mice (Figure 6A). To investigate the role of Atr deletion in the transition from AKI to CKD after IRI, ATR ${ }^{\text {RPTC- }- \text { a }}$ and control mice were subjected to 28 minutes of bilateral IRI. Decreased total kidney Atr mRNA was confirmed by qPCR in ATR ${ }^{\mathrm{RPTC}-/}$ mice on day 28 after IRI (Figure 6B). We observed no differences in serum creatinine or BUN at 24 hours, indicating similar degrees of initial injury in the ATR $^{\text {RPTC- }-}$ and ATR ${ }^{\text {Ctrl }}$ animals. However, 3 and 7 days after IRI, we observed delayed recovery among the ATR ${ }^{\mathrm{RPTC}-/}$ mice (Figure 6, $\mathrm{C}$ and $\mathrm{D}$ ), as reflected by persistent elevations in serum creatinine levels in $\mathrm{ATR}^{\mathrm{RPTC}-/-}$ mice compared with those in $\mathrm{ATR}^{\mathrm{Ctrl}}$ mice. The differences in creatinine levels persisted for at least 7 days, and differences in BUN persisted up to day 21 after IRI in $\mathrm{ATR}^{\mathrm{RPTC}-/}$ mice when compared with ATR ${ }^{\mathrm{Crrl}}$ mice (Figure 6D). Kidney histologic examination revealed substantially greater tissue damage (tubular dilation and loss of brush border) in $\mathrm{ATR}^{\mathrm{RPTC}-/}$ mice on day 7 after ischemic injury (Figure 6E). Twenty-eight days after IRI, when compared with ATR ${ }^{\mathrm{Ctrl}}$ mice, the $\mathrm{ATR}^{\mathrm{RPTC}-/-}$ mice had significantly more extracellular matrix collagen deposition, as quantified by Masson's trichrome (MT) staining (Figure 6F). Immunofluorescence (IF) staining of kidney cortices for $\alpha$-SMA expression was also greater in ATR ${ }^{\mathrm{RPTC}-/}$ mice, reflecting an increase in myofibroblast activation when compared with $\mathrm{ATR}^{\mathrm{Ctrl}}$ mice that had similar amounts of tubular injury at onset (Figure 6G). To quantify tubular cell loss, we measured the extent of KSP expression. $\mathrm{ATR}^{\mathrm{RPTC}-{ }_{-}}$mice had a greater reduction in $\mathrm{KSP}^{+}$tubular cell areas when compared with $\mathrm{ATR}^{\mathrm{Crrl}}$ animals, which was consistent with increased tubular atrophy (Figure 6G). In addition, real-time PCR analysis of kidney samples 28 days after IRI showed increased, or a tendency toward increased, mRNA levels of genes related to interstitial fibrosis (TGF- $\beta, \alpha$-SMA, collagen type $1 \alpha 1$ [Col1a1]) and the DDR (p21) in ATR ${ }^{\mathrm{RPTC}-/}$ mice compared with mRNA levels in ATR ${ }^{\mathrm{Crl}}$ mice (Figure 6, H-K). Twenty-eight days after IRI, more RPTECs were colabeled for both Ki67 (a marker of cell proliferation) and the $\mathrm{pH} 3$ (Ser10) among the $\mathrm{ATR}^{\mathrm{RPTC}-/}$ mice when compared with ATR ${ }^{\mathrm{Ctrl}}$ mice (Figure 7A), suggesting more RPTECs arrested at the $G_{2} / M$ phase of the cell cycle (48). Furthermore, RPTEC senescence-associated $\beta$-galactosidase (SA- $\beta$-gal) activity (a marker of secretory senescent cells) was increased to a greater degree in $\mathrm{ATR}^{\mathrm{RPTC}-/-}$ mice following IRI when compared with 


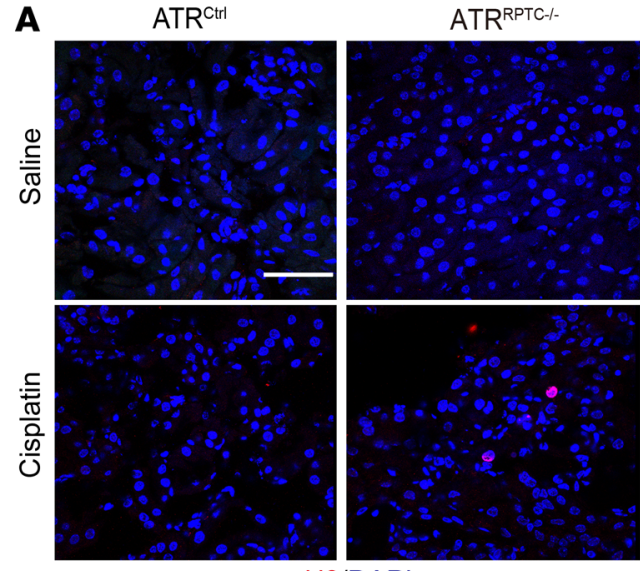

$\mathrm{pH} 3 / \mathrm{DAPI}$

B
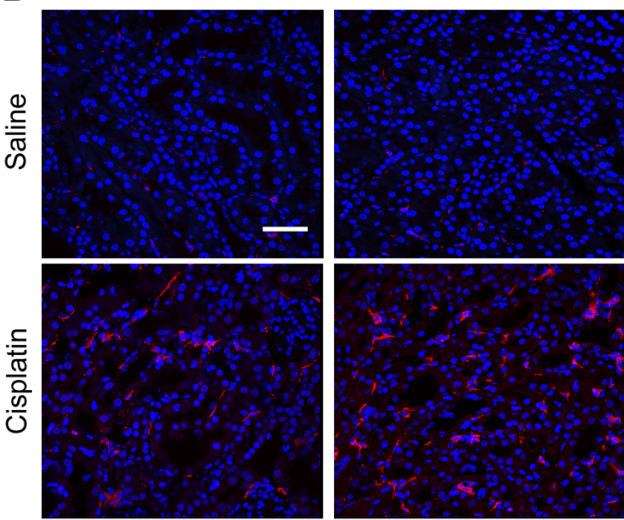

F4/80/DAP

E

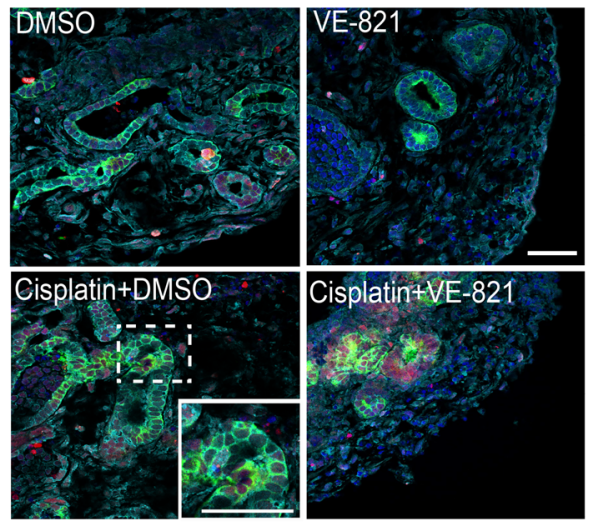

C

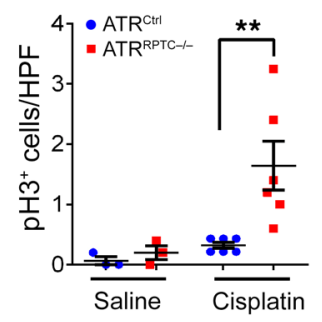

ATR RPTC-1-

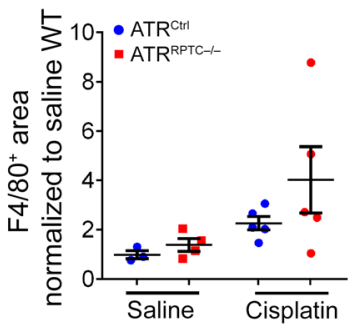

D
Cleaved caspase 3

$\beta$-Actin

Cisplatin $0.1 \mu \mathrm{g} / \mathrm{mL}$

VE-821 $10 \mu \mathrm{M}$ pretreatment

VE-821 $10 u M$

Mouse RTPCs
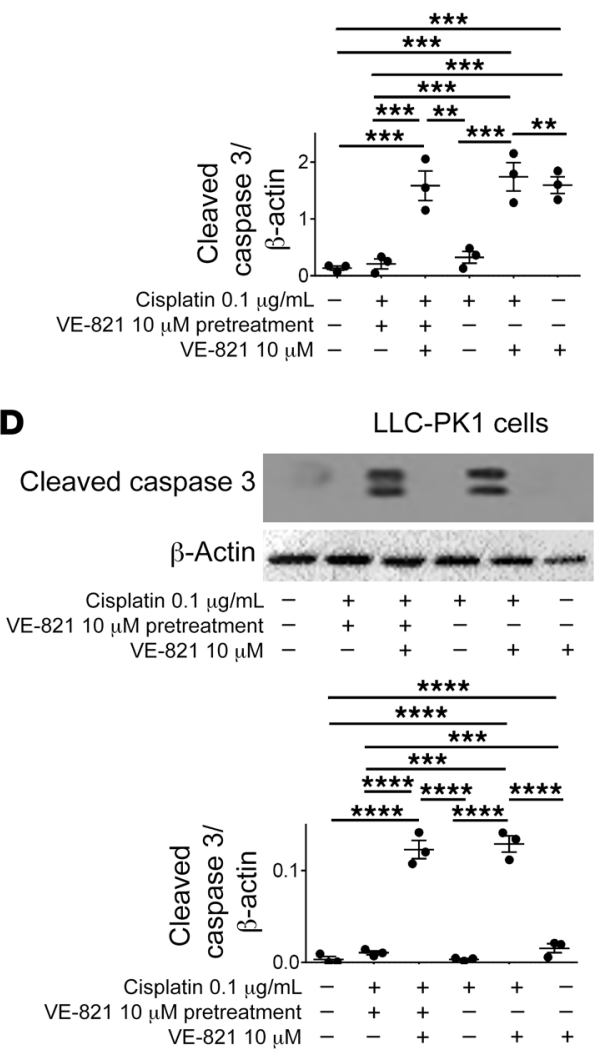

G

\section{F}

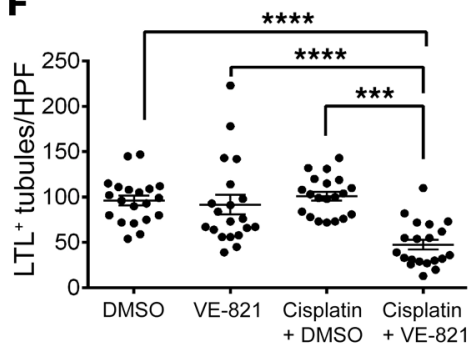

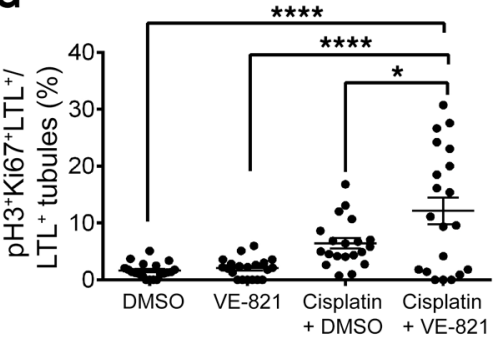

Figure 4. Atr gene deletion in RPTCs leads to increased cleaved caspase 3 and $\mathbf{G}_{2} / \mathbf{M}$-phase cells after cisplatin injection. (A) Representative images of pH3-stained kidney sections from $\mathrm{ATR}^{\mathrm{Ctrl}}$ and $\mathrm{ATR}^{\mathrm{RPTC}-/-}$ mice 96 hours after saline or cisplatin injection and the corresponding quantification of pH3 ${ }^{+}$ nuclei. Scale bar: $50 \mu \mathrm{m}$. Saline: $\operatorname{ATR}^{\mathrm{Ctrl}}(n=3)$, ATR ${ }^{\mathrm{RPTC}-/-}(n=4)$; cisplatin: $\operatorname{ATR}^{\mathrm{Ctrl}}(n=6)$, $\operatorname{ATR}^{\mathrm{RPTC}-{ }_{-}-}(n=6)$. (B) Representative images of F4/80-stained kidney sections from ATR ${ }^{\text {ctrl }}$ and ATR ${ }^{\text {RPTC-I- }}$ mice 96 hours after saline or cisplatin injection. Scale bar: $50 \mu \mathrm{m}$. Dot plot shows corresponding quantification of F4/80+ area. Saline: ATR ${ }^{\mathrm{ctrl}}(n=3)$, ATR ${ }^{\mathrm{RPTC}-I_{-}}(n=4)$; cisplatin: $\operatorname{ATR}^{\mathrm{Ctrl}}(n=5)$, ATR ${ }^{\mathrm{RPTC}-I_{-}}(n=5)$. Representative Western blots of cleaved caspase 3 expression in mouse RPTCs (C) and LLC-PK1 cells (D) treated with cisplatin, VE-821, or a combination of both. $n=3$ independent experiments. (E) Representative images of $\mathrm{H} 9$ cell-derived day-64 organoids treated with either cisplatin $(5 \mu \mathrm{M})$ or vehicle (DMSO) for 24 hours, with or without $10 \mu \mathrm{M}$ VE-821 pretreatment. Sections of the organoids were stained for LTL, pH3, Ki67, and DAPI. Scale bar: $50 \mu \mathrm{m}$; inset shows a high-power magnification of a triple-positive tubule. (F) Quantitation of $\mathrm{LTL}^{+}$tubules and (G) percentage of $\mathrm{pH3}^{+}$, Ki67 ${ }^{+}$, and $\mathrm{LTL}^{+}$cells to $\mathrm{LTL}^{+}$cells $(n=2 \times 10$ high-power fields [HPF] in each treatment group). Data are presented as the mean \pm SEM. Statistical significance was determined by 2-tailed, unpaired $t$ test (A and B, cisplatin ATR ${ }^{\text {ctrl }}$ vs. cisplatin ATR RPTC-I- $^{\mathrm{RP}}$ and 1-way ANOVA followed by Tukey's post-hoc test $(\mathbf{C}, \mathbf{D}, \mathbf{F}$, and $\mathbf{G}){ }^{*} P<0.05,{ }^{* *} P<0.01,{ }^{* *} P<0.001$, and ${ }^{* * * *} P<0.0001$. 
A

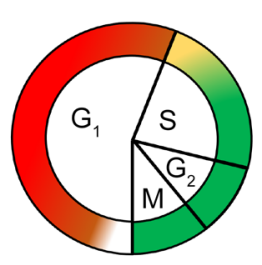

G phase

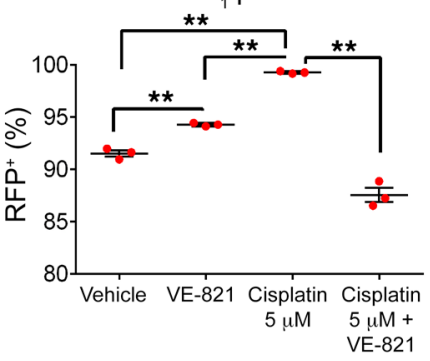

$\mathrm{S} / \mathrm{G}_{2} / \mathrm{M}$ phase

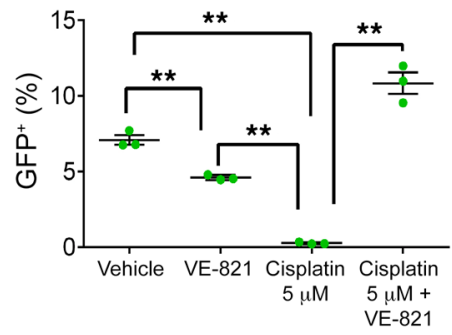

Early S phase

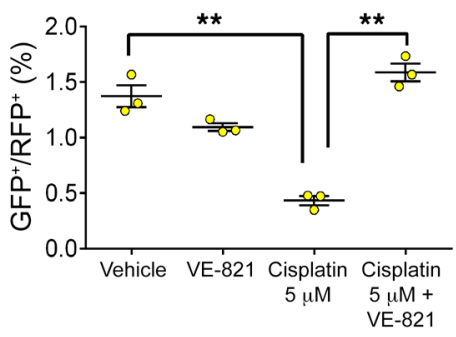

B

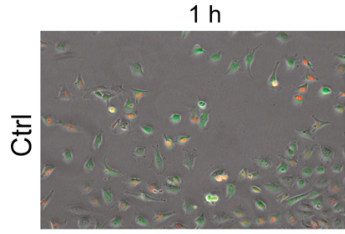

$\mathrm{mKO} / \mathrm{mAG} /$ bright-field
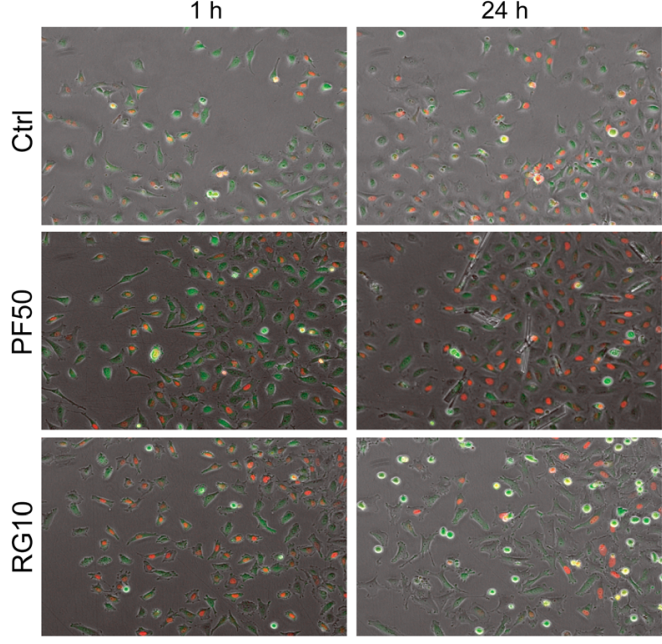

C

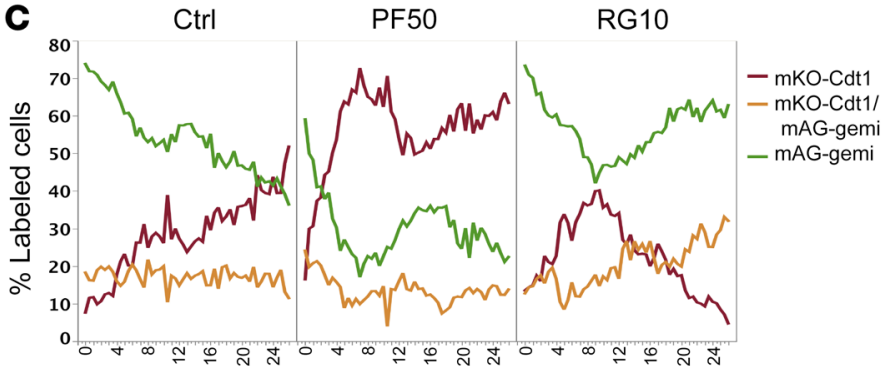

Ctrl

Duration (h)
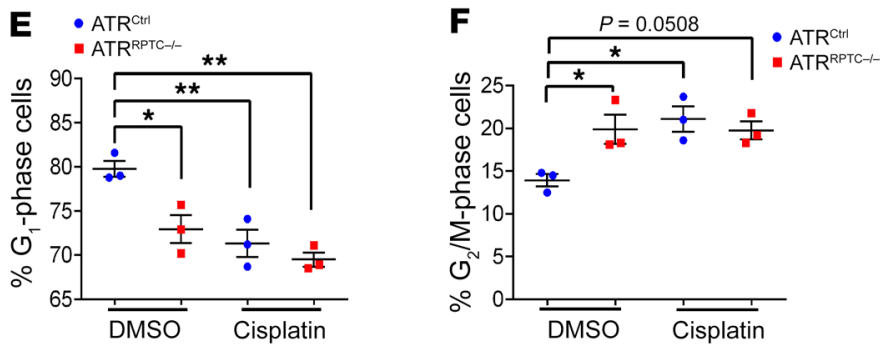

$\mathrm{mKO} / \mathrm{mAG}$

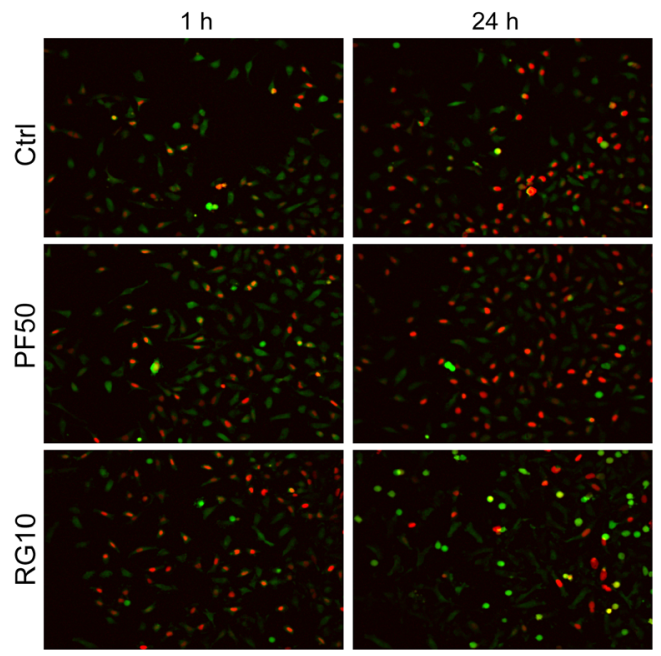

D
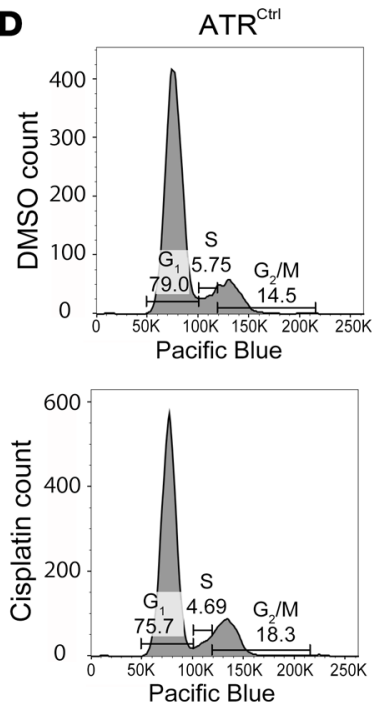

ATR ${ }^{\text {RPTC-r }}$
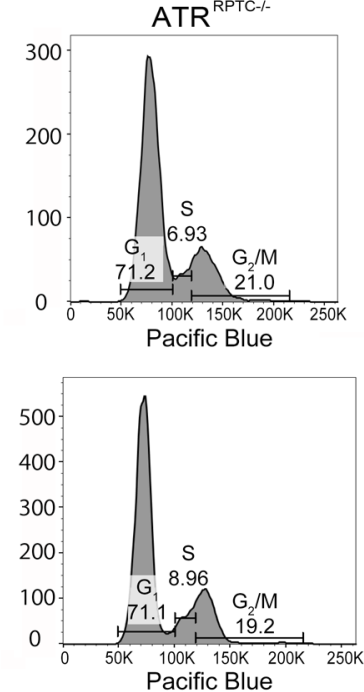

Figure 5. Atr deletion promotes $\mathbf{G}_{2} / \mathbf{M}$ arrest in cisplatin injured RPTECs. (A) Schematic diagram showing the timing of the FUCCI2a fluorescence reporters. Red indicates mCherry; green indicates mVenus. Dot plots show the cell-cycle profile and proportion of FUCCI RPTECs in $G_{1}$, early $S$, and $S / G_{2} / M$ phases, as analyzed by flow cytometry. Primary RPTECs from FUCCI2a-gGT-Cre mice were synchronized in 1\% FBS PTC media and then treated with cisplatin, with or without VE-821, or were left untreated for 48 hours. Cells were then fixed and analyzed by flow cytometry. Red and green colors in the graph indicate $G_{1}$ and $S / G_{2} / M$ phases, respectively, and double-positive cells were considered to be in the early $S$ phase. RFP, red fluorescent protein; $G F P$, green fluorescent protein. (B and C) Cell-cycle assessment by live microscopy of HK2 cells expressing the FUCCI system in control conditions (Ctrl, $n=4$ ), or incubated with $50 \mathrm{nM}$ pifithrin- $\alpha(P F 50, n=2)$ or $10 \mathrm{nM}$ rigosertib (RG10, $n=2)$. (B) Representative images of the cells at 1 hour and 24 hours after incubation are shown. Images on the left show overlays of bright-field, monomeric Kusabira-Orange (mKO), and monomeric Azami-Green (mAG) channels. Images on the right show mKO and mAG channels (original magnification, $\times 10$ ). (C) Graph shows the quantification over time of the cells in $\mathrm{G}_{1}$ (mKO-Cdt1, red), $G_{2}$ (mAG-geminin, green), and S (mKO-Cdt1+ mAG-geminin, orange) phases of the cell cycle. (D) Cell-cycle analysis by propidium iodide staining and flow cytometry of mouse primary cells at baseline (top 2 graphs) and after treatment with cisplatin at $0.2 \mu \mathrm{g} / \mathrm{mL}$ for 48 hours (bottom 2 graphs). (E and $\mathbf{F}$ ) Results of the cell-cycle analysis for 3 independent experiments. Data are presented as the mean $\pm \mathrm{SEM}$. Statistical significance was determined by 1 -way ANOVA followed by Tukey's post hoc test. ${ }^{*} P<0.05$ and ${ }^{* *} P<0.01$. 

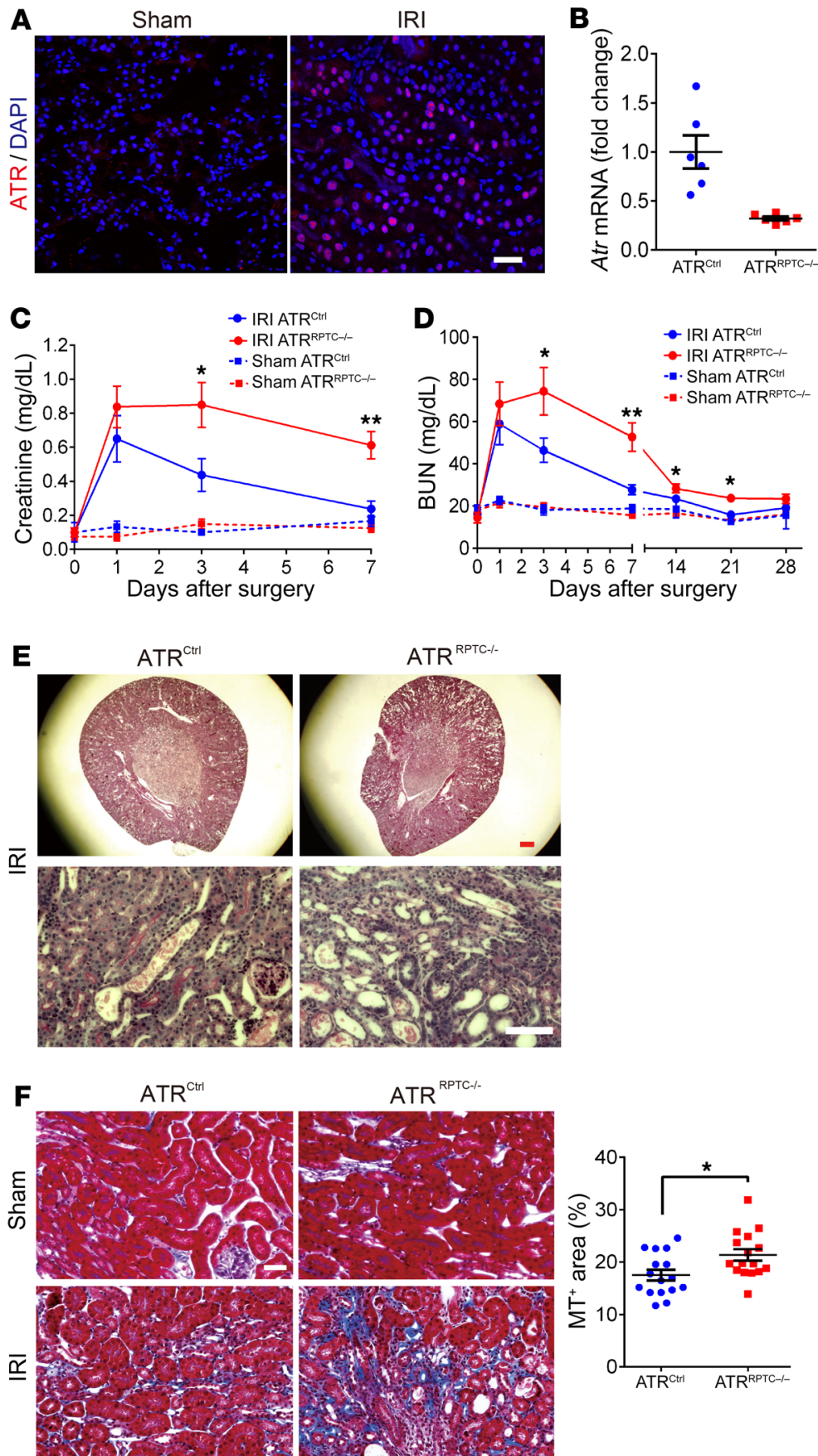

G
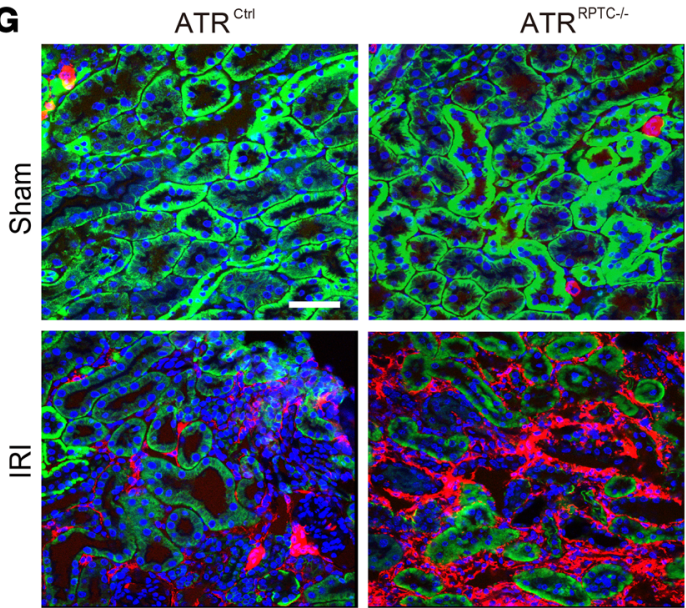

KSP/a-SMA/DAPI
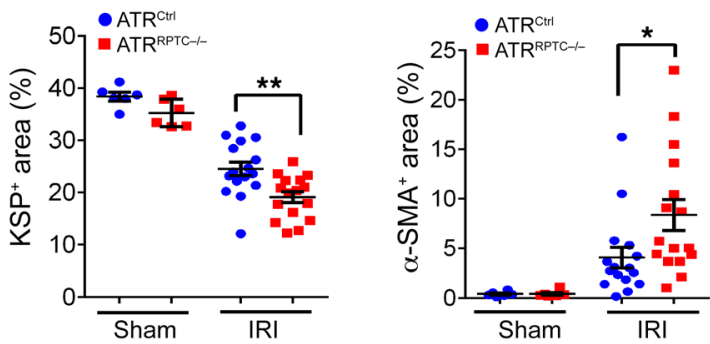

H
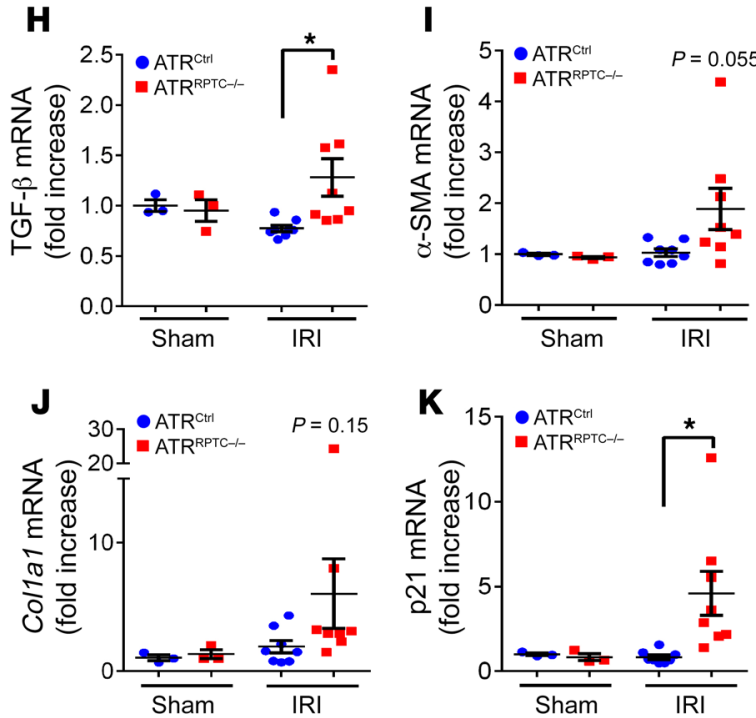

Figure 6. Atr gene depletion in RPTECs results in increased profibrotic changes after IRI. (A) Representative images of ATR-stained sections of kidneys 48 hours after IRI or sham operation. Scale bar: $50 \mu \mathrm{m}$. (B) Real-time PCR analysis of Atr mRNA levels in ATR ${ }^{\text {Ctrl }}$ and ATR ${ }^{\text {RPTC-I- }}$ kidneys on day 28 after IRI. $\operatorname{ATR}^{\mathrm{Ctrl}}(n=6)$, ATR RPTC-I- $(n=6)$. (C and D) Changes in serum creatinine and BUN following IRI. Sham operation: ATR ${ }^{\mathrm{Ctrl}}(n=3)$, ATR ${ }^{\mathrm{RPTC}-I_{-}}(n=3)$; IRI: ATR ${ }^{\mathrm{Ctrl}}$ $(n=8)$, ATR RPTC-I- $(n=8)$. (E) Representative images of PAS-stained kidneys from ATR ${ }^{\text {ctrl }}$ and ATR APTC- - mice on day 7 after IRI. Scale bars: $300 \mu m$ (top) and $50 \mu \mathrm{m}$ (bottom). (F) Representative images of MT-stained kidneys from ATR ${ }^{\mathrm{Ctrl}}$ and ATR $^{\mathrm{RPTC}-1-}$ mice on day 28 after IRI or sham operation. Dot plot shows the quantification of the $\mathrm{MT}^{+}$area. Scale bar: $100 \mu \mathrm{m}$. (C) Representative images of KSP- and $\alpha$-SMA-stained kidney sections from ATR ${ }^{\mathrm{Ctrl}}$ and ATR $^{\mathrm{RPTC}-\mathrm{I}^{-}}$ mice 28 days after IRI or sham operation. Dot plots show the quantification of $\mathrm{KSP}^{+}$and $\alpha-\mathrm{SMA}^{+}$areas. Scale bar: $50 \mu \mathrm{m}$. $(\mathbf{F}$ and $\mathbf{G}) \mathrm{Sham}^{\mathrm{A}}$ : ATR ${ }^{\mathrm{ctrl}}(n=3$ mice, 6 kidneys), ATR ${ }^{\text {RPTC-I- }}\left(n=3\right.$ mice, 6 kidneys); IRI: ATR ${ }^{\text {ctrl }}\left(n=8\right.$ mice, 16 kidneys), ATR ${ }^{\text {RPTC-I- }}(n=8$ mice, 16 kidneys). (H-K) RT-PCR analysis of TGF- $\beta$,

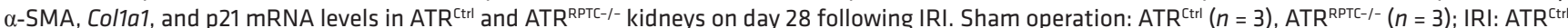
$(n=8)$, ATR ${ }^{\text {RPTC- }--}(n=8)$. Data are presented as the mean \pm SEM. Statistical significance was determined by 2-tailed, unpaired $t$ test (IRI ATR ${ }^{\text {Ctrl }}$ vs. IRI ATR RPTC- - ). $^{*} P<0.05$ and ${ }^{* *} P<0.01$. 
A
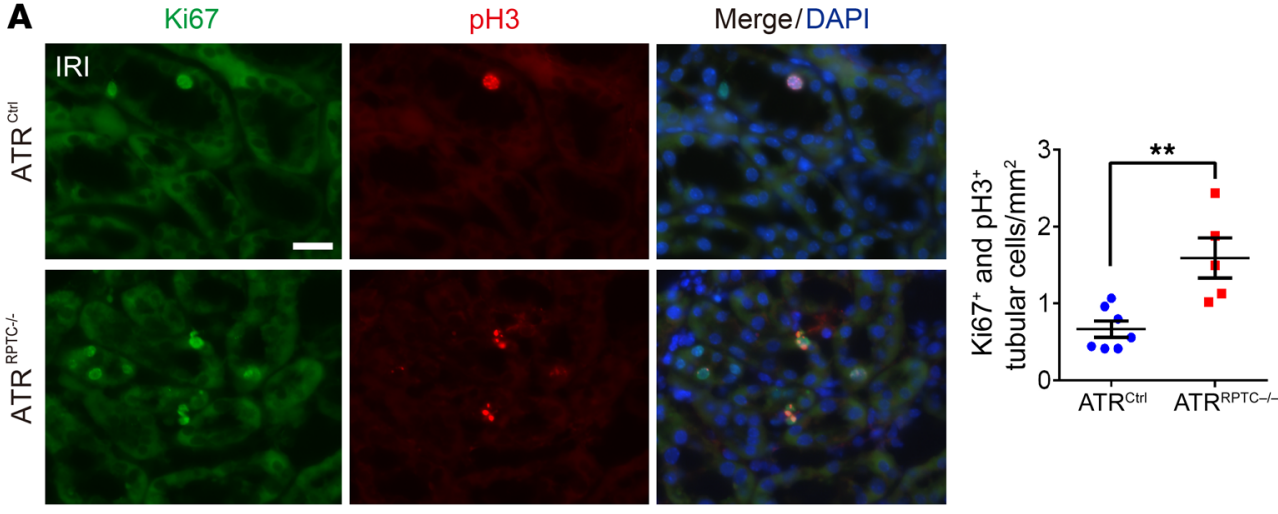

B
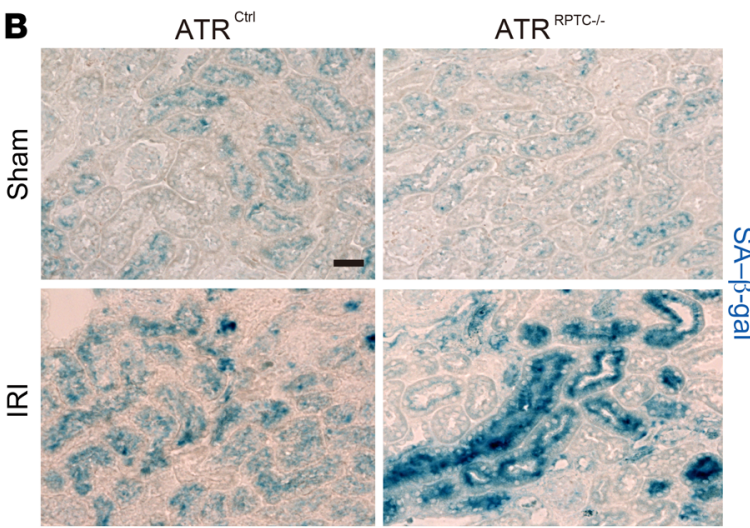

Figure 7. Atr gene depletion in RPTECs results in $G_{2} / M$ arrest and cellular senescence after IRI. (A) Representative images of coimmunostaining with antibodies against $\mathrm{Ki} 67$ and $\mathrm{pH} 3$ in cells from ATR $^{\mathrm{ctrl}}$ and ATR $^{\text {RPTC-I- }}$ mice on day 28 following IRI and the corresponding quantification of $\mathrm{Ki}^{+} 7^{+}$and $\mathrm{pH}^{+}$nuclei. ATR ${ }^{\mathrm{ctrl}}(n=7)$ $\operatorname{ATR}^{\mathrm{RPTC}-I_{-}}(n=5)$. Scale bar: $50 \mu \mathrm{m}$. (B) Representative images of $S A-\beta$-galstained kidney sections from ATR ${ }^{\text {trr }}$ and ATR ${ }^{\text {RTTC-I- }}$ mice 28 days after IRI or sham operation. Scale bar: $50 \mu \mathrm{m}$. Dot plots shows the quantification of SA- $\beta$-gal ${ }^{+}$areas. IRI: ATR $^{\mathrm{Ctrl}}$ and ATR $^{\text {RPTC-I- }}$ mice ( $n=5$ mice and 10 kidneys). Data are presented as the mean \pm SEM. Statistical significance was determined by 2-tailed, unpaired $t$ test (IRI ATR ${ }^{\text {ctrl }}$ vs. IRI ATR ${ }^{\text {RPTC-I- }}$ ). ${ }^{*} P<0.05$ and ${ }^{*} P<0.01$ activity in ATR $\mathrm{R}^{\mathrm{Ctrl}}$ animals (Figure 7B). Taken together, these data suggest that a lack of ATR in RPTECs predisposes kidneys to maladaptive repair, with increased numbers of RPTECs in the $G_{2} / M$ cell-cycle phase, increased senescence, and increased fibrosis following tubular injury.

Deletion of the RPTEC Atr gene results in more severe kidney inju$r y$, increased DNA damage, apoptosis, $G_{2} / M$-phase cells, and fibrosis after UUO. As the third model of kidney injury, we investigated the role of RPTEC ATR in the development of kidney fibrosis after UUO. DNA damage and DNA repair activity are related to the progression of kidney fibrosis after UUO $(49,50)$. ATR $^{\mathrm{RPTC}-/-}$ mice had a higher histological tubular injury score 7 days after UUO compared with $\mathrm{ATR}^{\mathrm{C} \text { Crl }}$ mice (Figure $8 \mathrm{~A}$ ). In addition, KIM-1 was more highly expressed at the protein level 7 days after UUO in $\mathrm{ATR}^{\mathrm{RPTC}-1-}$ mice (Figure 8, B and C). Coincident with enhanced kidney injury, we found that the number of $\gamma \mathrm{H} 2 \mathrm{AX}^{+}$cells on day 7 after UUO was significantly increased in $\mathrm{ATR}^{\mathrm{RPTC}-/-}$ mice when compared with $\mathrm{ATR}^{\mathrm{Ctrl}}$ animals exposed to UUO. Both the number of cells with nucleus-wide $\gamma \mathrm{H} 2 \mathrm{AX}$ expression and the number of $\gamma \mathrm{H} 2 \mathrm{AX}$ foci were significantly increased in $\mathrm{ATR}^{\mathrm{RPTC}-/-}$ mice when compared with $\mathrm{ATR}^{\mathrm{Ctrl}}$ animals (Figure 8D). Furthermore, apoptosis, as measured by cleaved caspase 3 staining, was also significantly greater in $\mathrm{ATR}^{\mathrm{RPTC}-/-}$ mice (Figure 8E). These results indicated that the lack of ATR in RPTECs leads to an increase in the amount of DNA damage and apoptosis after UUO.

MT staining revealed greater collagen content in $\mathrm{ATR}^{\mathrm{RPTC}-/}$ mice compared with ATR $^{\mathrm{Ctrl}}$ mice in the UUO model (Figure 9A). Moreover, $\mathrm{ATR}^{\mathrm{RPTC}-/-}$ mice had a significant increase in kidney $\alpha$-SMA ${ }^{+}$area after UUO and a decrease in $\mathrm{KSP}^{+}$tubular cells compared with $\mathrm{ATR}^{\mathrm{Ctrl}}$ mice (Figure 9B). The contralateral kidney (CLK) was used as a control for the obstructed kidney. We noted no significant differences between the CLKs of ATR ${ }^{\mathrm{Ctrl}}$ and $\mathrm{ATR}^{\mathrm{RPTC}-1-}$ mice in terms of mRNA expression levels of kidney fibrosis markers including TGF- $\beta$, connective tissue growth factor (CTGF), $\alpha$-SMA, COL1 $\alpha 1$, fibronectin, and PDGFR- $\beta$. By contrast, mRNA levels of all these fibrotic markers, with the exception of PDGFR- $\beta$, which showed a definite trend toward higher expression $(P=0.079)$, were more significantly upregulated in $\mathrm{ATR}^{\mathrm{RPTC}-/-}$ mice in response to UUO than in $\mathrm{ATR}^{\mathrm{Ctrl}}$ mice (Figure 9, C-H). There were no differences in the number of $\mathrm{Ki}^{6} 7^{+}$cells between $\mathrm{ATR}^{\mathrm{RPTC}-/-}$ and $\mathrm{ATR}^{\mathrm{Ctrl}}$ kidneys following UUO (Figure 9I), and the majority of the Ki67 $7^{+}$cells did not stain with $\mathrm{F} 4 / 80$ or $\alpha$-SMA (Figure 9J). Similar to the results we observed with cisplatin-induced kidney injury (Figure 4A) and IRI (Figure 7A), $\mathrm{ATR}^{\mathrm{RPTC}-/}$ mice had increased numbers of cells in the $G_{2} / \mathrm{M}$ phase of the cell cycle $\left(\mathrm{pH}^{+}\right) 7$ days after UUO compared with ATR $^{\text {Ctrl }}$ mice (Figure 9K), a finding consistent with enhanced $\mathrm{G}_{2} / \mathrm{M}$ arrest. We detected a tendency toward increased mRNA expression of p53 and a significant increase in its direct target p21 in $\mathrm{ATR}^{\mathrm{RPTC} /-}$ mice compared with expression levels in littermate controls after UUO (Figure 9, L and M). These results indicate that RPTEC Atr deletion leads to increased kidney fibrosis and numbers of RPTECs in the $\mathrm{G}_{2} / \mathrm{M}$ phase following UUO.

ATR inhibition or deletion increases the formation of TASCCs in RPTECs in human kidney organoids and mice after injury. Recent studies have identified the formation of target of rapamycin-autophagy spatial coupling compartments (TASCCs) as key components of the senescence-associated secretory phenotype $(25,51)$. 
A

ATR $^{\mathrm{CtrI}}$

ATR RTC-1-
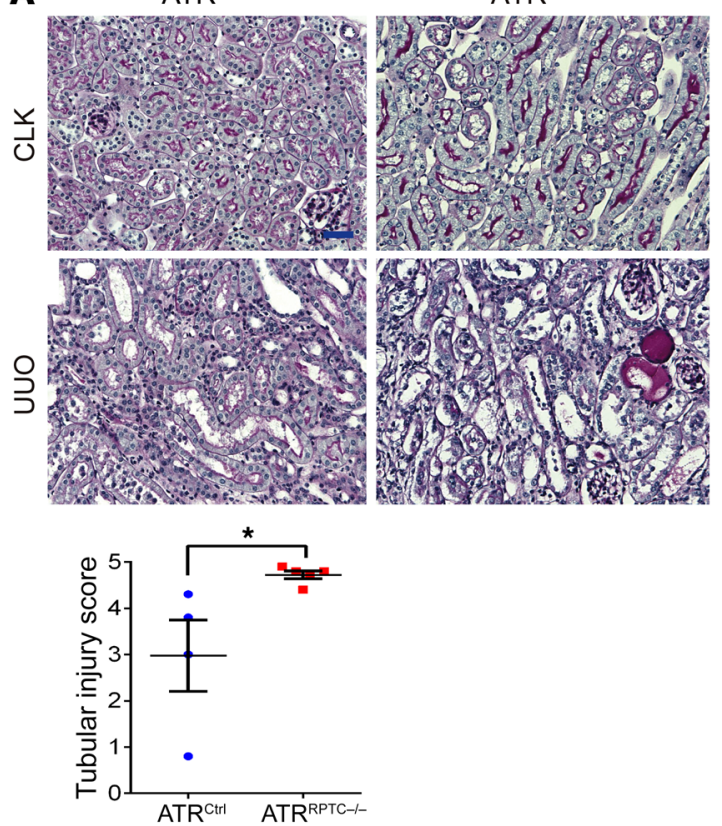

B
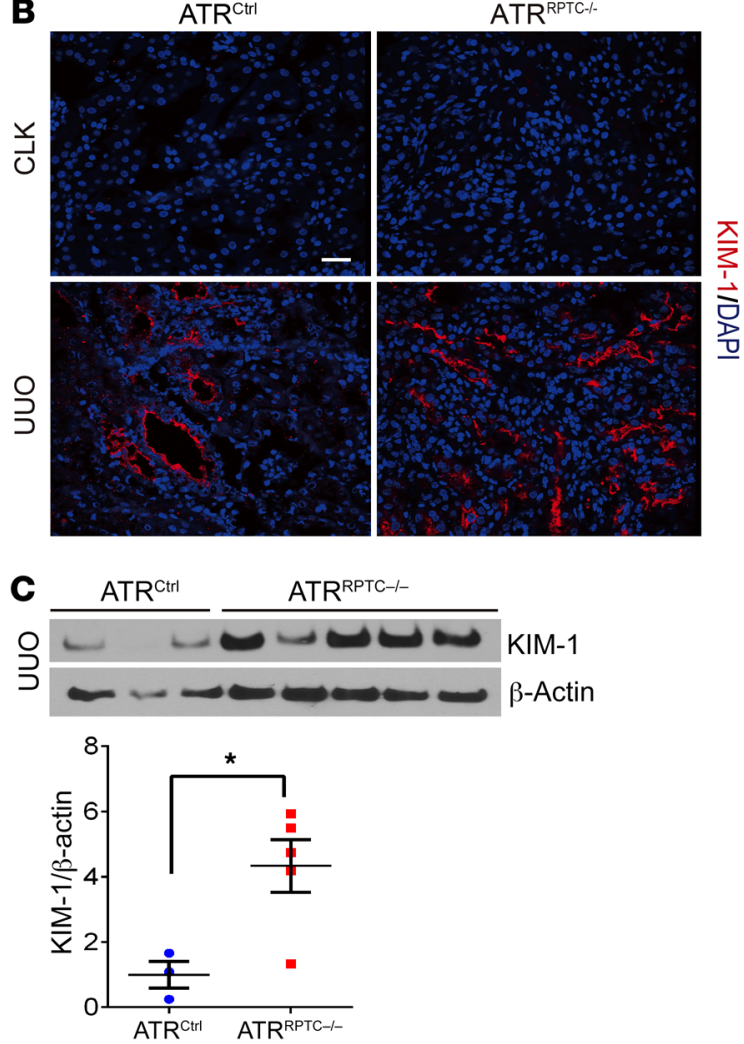

D
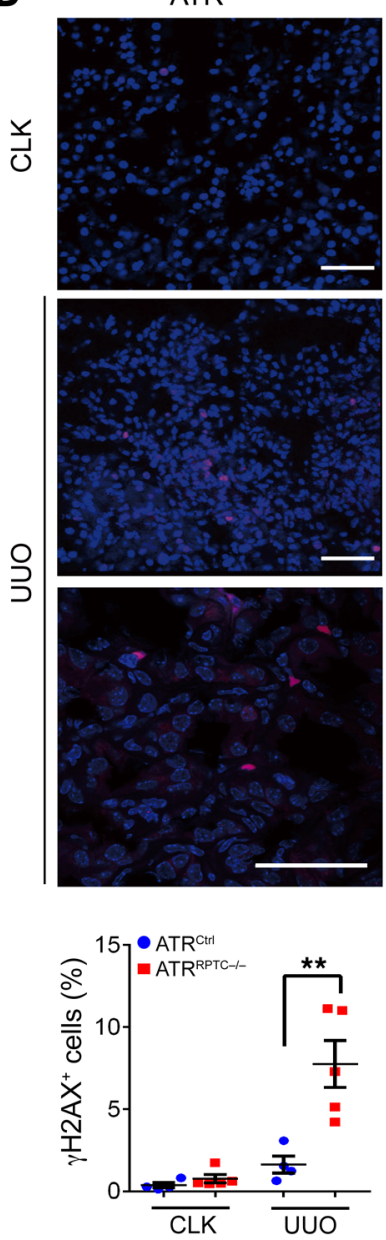

E
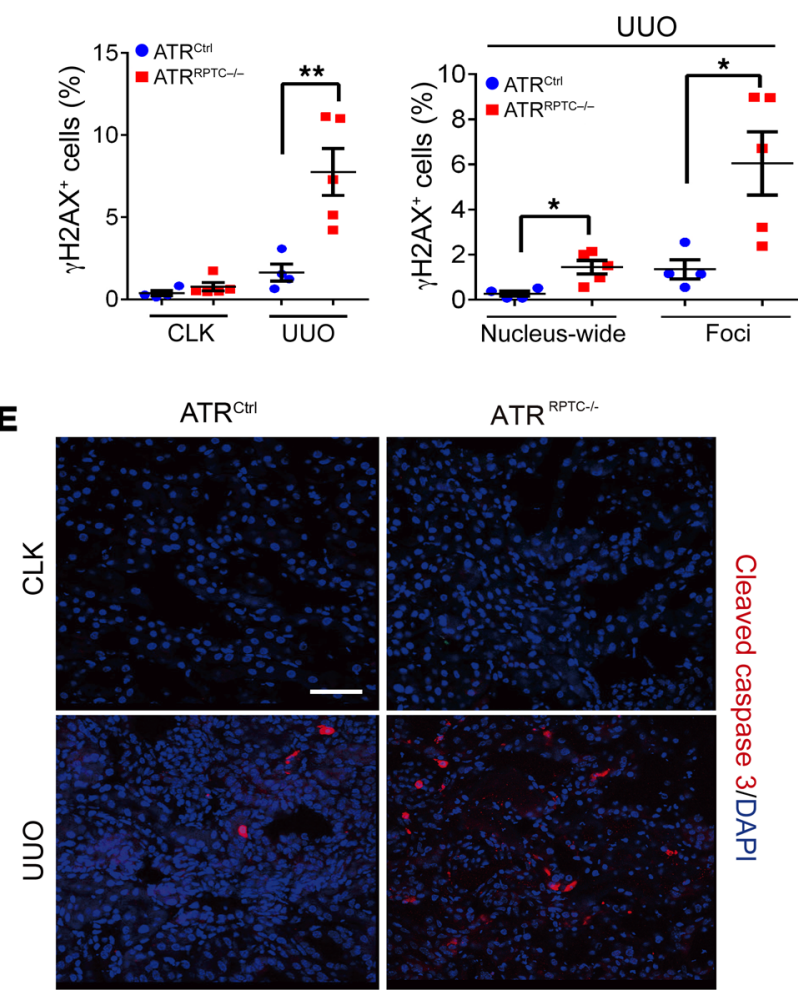

$\mathrm{ATR}^{\mathrm{RPTC}-1}$

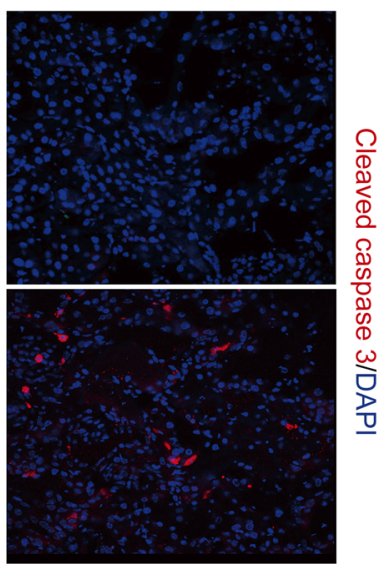


Figure 8. Deletion of RPTEC Atr results in more severe kidney injury and increased DNA damage and cleaved caspase 3 after UUO. (A) Representative kidney histological images of PAS-stained kidney sections 7 days after UUO. Scale bar: $50 \mu \mathrm{m}$. Dot plot shows quantified tubular injury score. ATR ${ }^{\mathrm{Ctrl}}(n=4)$, ATR ${ }^{\mathrm{RPTC}-1-}(n=5)$. (B) Representative images of KIM-1-

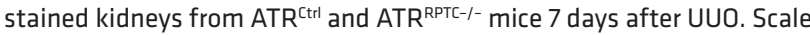
bar: $50 \mu \mathrm{m}$. (C) Western blotting was performed on UUO-injured kidney Iysates to determine KIM-1 expression. Each lane represents 1 sample from an individual mouse. Dot plot shows the corresponding quantification of band intensity. ATR ${ }^{\mathrm{Ctrl}}(n=3)$, ATR ${ }^{\mathrm{RPTC}-I_{-}}(n=5)$. (D) Representative images of $\gamma \mathrm{H} 2 \mathrm{AX}$-stained sections of CLKs and injured kidneys from ATR ${ }^{\mathrm{ctrl}}$ and $A T R^{\mathrm{RPTC}-1-}$ mice 7 days after UUO. Dot plots show the corresponding quantification of $\gamma \mathrm{H} 2 \mathrm{AX}^{+}$cells and of nucleus-wide $\gamma \mathrm{H} 2 \mathrm{AX}{ }^{+}$and $\gamma \mathrm{H} 2 \mathrm{AX}{ }^{+}$ foci. $\operatorname{ATR}^{\mathrm{Ctrl}}(n=4)$, ATR ${ }^{\mathrm{RPTC}-/-}(n=5)$. Scale bars: $50 \mu \mathrm{m}$. (E) Representative images of cleaved caspase 3-stained sections of CLKs and injured kidneys from ATR ${ }^{\mathrm{Ctrl}}$ and $\mathrm{ATR}^{\mathrm{RPTC}-\mathrm{-}-}$ mice 7 days after UUO. Scale bar: $50 \mu \mathrm{m}$. Dot plot shows the corresponding quantification of cleaved caspase $3^{+}$cells. $\operatorname{ATR}^{\mathrm{Ctrl}}(n=4), \operatorname{ATR}^{\mathrm{RPTC}-I_{-}}(n=5)$. Data are presented as the mean $\pm \mathrm{SEM}$. Statistical significance was determined by 2-tailed, unpaired $t$ test (UUO ATR $^{\mathrm{Ctr}}$ vs. ATR $\left.{ }^{\mathrm{RPTC}-}-{ }_{-}\right)$. ${ }^{*} P<0.05$ and ${ }^{* *} P<0.01$. The complete unedited blots are provided in the supplemental material.

We identified TASCC formation in humans and animal models with CKD and linked it to the progression of kidney fibrosis in CKD (25). TASCC formation is critical for the AKI-to-CKD transition, since inhibition of TASCCs after the injury phase of AKI prevents CKD (25). To evaluate whether ATR inhibition increased TASCC formation, we treated kidney organoids with cisplatin. TASCC formation was significantly elevated 24 hours after cisplatin exposure and remained elevated over the long term (120 hours) (Figure 10A). We also examined TASCC formation in $\mathrm{ATR}^{\mathrm{RPTC} /-}$ mice. Following UUO, we found that TASCC formation was significantly increased in $\mathrm{ATR}^{\mathrm{RPTC} /-}$ mice compared with littermate controls (Figure 10B and Supplemental Video 1), as evaluated by super-resolution structured illumination microscopy (SIM). These data suggest that ATR inhibition or deletion promotes fibrosis in part by inducing the formation of TASCCs.

\section{Discussion}

This study reveals, for the first time to our knowledge, the importance of a DDR protein in post-injury repair in RPTECs, which comprise approximately $80 \%$ to $90 \%$ of the kidney cortex. Our previous study, as well as subsequent studies by other investigators, demonstrated that maladaptive DNA repair, with RPTECs arrested in the $G_{2} / M$ phase of the cell cycle, is an important mechanism underlying the progression from $\operatorname{AKI}$ to $\operatorname{CKD}(7,52)$. We hypothesized that RPTEC-specific deletion of a DDR mediator would cause a reduction in DDR signaling, decrease adaptive repair after injury, and hasten chronic fibrotic changes to the kidney due to dysfunctional DNA repair. We found that ATR, a sensor of DNA damage and an initiator of the DDR signaling cascade (53, $54)$, was activated in patients with CKD and in mice with different models of CKD. We studied the role of RPTEC ATR in 3 different mouse models of tubular injury: cisplatin nephrotoxicity, ischemia-reperfusion, and UUO, as well as in RPTECs in culture and human kidney organoids. Each type of tubular insult has been shown to cause DNA damage in RPTECs through alkylation, oxidative stress, or oxygen free radical release $(7,9,25,55)$. Atr constitutive gene loss results in embryonic lethality (56), making it essential to use a conditional inducible system in mouse models of disease. At baseline, we found that similar levels of acute tubular injury were generated in either $\mathrm{ATR}^{\mathrm{RPTC}-/-}$ or $\mathrm{ATR}^{\mathrm{Ctrl}}$ mice after ischemia. Despite the similar degree of injury during the acute phase of injury, we observed a difference in the repair and chronic phases of injury in the $\mathrm{ATR}^{\mathrm{RPTC}-/-}$ mice, which developed more maladaptively injured cells in the $\mathrm{G}_{2} / \mathrm{M}$ phase and more fibrosis compared with ATR $^{\text {Ctrl }}$ mice. In the UUO model, which is characterized by greatly accelerated fibrosis, we observed increased tubular injury and fibrosis in $\mathrm{ATR}^{\mathrm{RPTC}-/-}$ mice. With cisplatin injury, the maladaptive repair in $\mathrm{ATR}^{\mathrm{RPTC}-/-}$ mice was associated with increased apoptosis, markers of kidney injury, and cell death when compared with ATR ${ }^{\mathrm{Ctrl}}$ mice. Experiments in both human kidney organoids and RPTEC lines confirmed that ATR inhibition promoted caspase activation and resulted in more cells in the $G_{2} / M$ phase of the cell cycle in response to cisplatin injury.

Previous studies by our group and others have shown that surviving TECs are stimulated to proliferate in order to replace lost RPTECs after AKI, and the severity of the injury determines the long-term outcome $(3,21-24)$. Maladaptive repair associated with $\mathrm{G}_{2} / \mathrm{M}$ arrest can lead to senescence and fibrosis. In the DDR pathway, ATM, ATR, and p53 play critical roles in regulating the balance between cell survival and death $(24,57)$. When DNA damage is relatively mild, the DDR can repair the DNA and prevent cell death. On the other hand, when the damage is severe, the DDR can induce tubular cells to go into cell-cycle arrest or apoptosis. In this study, we showed that, compared with WT mice, inhibition of the DDR in kidney RPTECs by genetic inactivation of Atr expression led to increased expression of markers of DNA damage and kidney injury as well as greater functional impairment following kidney injury. In effect, we reduced the number of cells that could contribute to recovery. In addition, deletion or inhibition of ATR also resulted in an increase in maladaptive repair, cell-cycle arrest at the $G_{2} / M$ checkpoint, and subsequent fibrosis and CKD. Thus, the maladaptive response includes inadequate salvaging of sublethally injured cells to replace lost cells as well as cell-cycle arrest, i.e., $G_{2} / M$ arrest, in surviving cells, which contributes to longer-term tissue injury and $\operatorname{CKD}(7,57)$.

Following injury and induction of DNA damage, ATR-deficient cells have been shown to bypass the $G_{2} / M$ checkpoint first and undergo mitosis, but with daughter cells that have persistently unrepaired DNA damage that undergo more $\mathrm{G}_{2} / \mathrm{M}$ arrest $(20,48)$. Cumulative unresolved DNA damage can cause cells to undergo permanent cell-cycle arrest and senescence or, alternatively, may cause cell death through apoptosis $(15,56)$. We confirmed that $\mathrm{G}_{2} / \mathrm{M}$ arrest occurred in our models by performing flow cytometric analysis of primary RPTECs expressing FUCCI2a, using recently published methods that rule out other sources of $>2 n$ DNA such as polyploidy (58), which recent data suggest is not as prominent as had been previously reported (58). Thus, pathways such as the DDR that control the fate of cells can determine the outcome of kidney injury and provide important clues to therapeutic targets.

The DDR is a cellular mechanism that has evolved over time for the detection and repair of DNA strand breaks resulting from a myriad of endogenous and exogenous factors. Although the DDR generally protects against disease, hypo- or hyperactivation can result in a less efficient DDR that contributes to human patholo- 

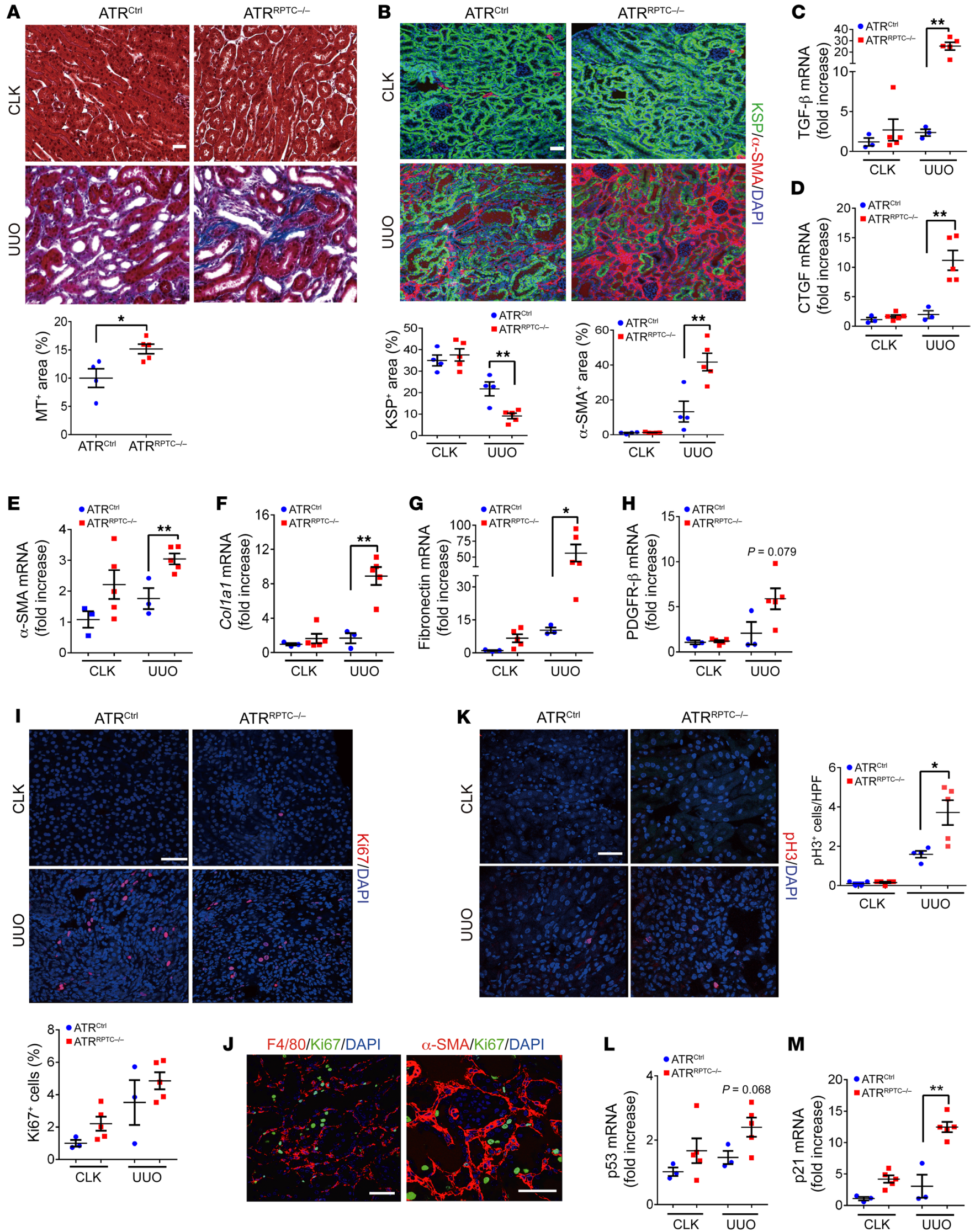

M

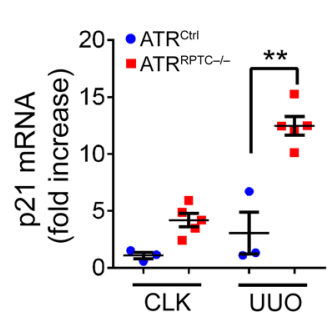


Figure 9 . The increase in fibrosis and $G_{2} / M$ phase cell cycle is greater in ATR $^{\text {RPTC-I- }}$ mouse kidneys after UUO. (A) Representative kidney histological images of MT-stained sections 7 days after UUO and corresponding quantification of $\mathrm{MT}^{+}$areas. $\operatorname{ATR}^{\mathrm{ctrl}}(n=4), \operatorname{ATR}^{\mathrm{RPTC}-\text { - }^{-}}(n=5)$. Scale bar: 50 $\mu \mathrm{m}$. (B) Representative images of KSP- and $\alpha$-SMA-stained sections of CLKs and injured kidneys from ATR ${ }^{\mathrm{Ctrl}}$ and $\mathrm{ATR}^{\mathrm{RPTC}-{ }_{-}}$mice on day 7 . Scale bar: $50 \mu \mathrm{m}$. Dot plots show quantification of $\mathrm{KSP}^{+}$and $\alpha-\mathrm{SMA}^{+}$areas. $\operatorname{ATR}^{\mathrm{Ctrl}}(n=4)$, ATR ${ }^{\mathrm{RPTC}-1-}(n=5)$. (C-H) Quantitative RT-PCR analysis of TGF- $\beta$, CTCF, $\alpha-S M A$, Col1a1, fibronectin, PDGFR- $\beta$, p53, and p21 mRNA levels in kidneys from ATR ${ }^{\mathrm{ctrl}}$ and $\mathrm{ATR}^{\mathrm{RPTC}-/-}$ mice on day 7 . $\operatorname{ATR}^{\mathrm{ctrl}}(n=3)$, $\operatorname{ATR}^{\text {RPTC-/- }}(n=5)$. (I) Representative images of Ki67-stained sections of CKLs and injured kidneys from ATR $^{\mathrm{Ctrl}}$ and $\mathrm{ATR}^{\mathrm{RPTC}-/-}$ mice on day 7. Scale bar: $50 \mu \mathrm{m}$. Dot plot shows the corresponding quantification of $\mathrm{Ki}^{+} 7^{+}$ cells. $\operatorname{ATR}^{\text {ctrl }}(n=4)$, ATR RPTC-I- $(n=5)$. (J) Representative images of F4/80and Ki67-stained and $\alpha$-SMA- and Ki67-stained sections of injured kidneys from ATR ${ }^{\mathrm{RPTC}-1-}$ mice on day 7 . Scale bars: $50 \mu \mathrm{m}$. (K) Representative images of $\mathrm{pH} 3$-stained sections of CLKs and injured kidneys from ATR ${ }^{\mathrm{ctr}}$

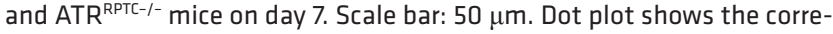
sponding quantification of $\mathrm{pH}^{+}$nuclei. ATR ${ }^{\mathrm{Ctrl}}(4), \operatorname{ATR}^{\mathrm{RPTC}-\text { - }^{-}}(n=5)$. ( $\mathrm{L}$ and M) Quantitative RT-PCR analysis of $p 53$ and p21 mRNA levels in kidneys from ATR ${ }^{\mathrm{Ctrl}}$ and $\mathrm{ATR}^{\mathrm{RPTC}-1-}$ mice on day 7. ATR ${ }^{\mathrm{Ctrl}}(n=3), \operatorname{ATR}^{\mathrm{RPTC}-l-}(n=$ 5 ). Data are presented as the mean \pm SEM. Statistical significance was determined by 2-tailed, unpaired $t$ test (UUO ATR ${ }^{\mathrm{Ctrl}}$ vs. UUO ATR ${ }^{\mathrm{RPTC}-{ }^{-}-}$). ${ }^{*} P<0.05$ and ${ }^{*} P<0.01$.

gy $(59,60)$. Mutations of the DDR pathway in humans have been associated with progeroid-like syndromes with clinical features of early-onset aging, such as Werner syndrome, Cockayne syndrome, and ataxia-telangiectasia (61). CKD can be considered a state of accelerated aging of the kidney (62), and aging is also a significant risk factor for worsening renal function (62). Senescence is thought to be a major contributor to the aging process (63) through telomeric attrition during the normal cell replication process, eventually leading to a state of permanent cell-cycle arrest $(64,65)$. Maladaptive DNA repair with arrest of kidney epithelial cells in the $G_{2} / M$ phase of the cell cycle, leading to kidney fibrosis after tubular injury (7), is similar to what is often observed in aging in the kidney (62). More severe or repeated kidney injury, each a feature of CKD and aging, leads to more DNA damage, more cell-cycle arrest, generation of profibrotic cytokines, and acceleration of kidney fibrosis $(8,62)$. Loss-of-function mutations in DDR signaling lead to premature aging in animal models $(19,20,66)$. In the current study, deletion of the Atr gene in RPTECs resulted in phenotypes similar to those seen in aged kidneys, including increased susceptibility to fibrosis, accumulation of DNA damage, and cellular senescence. RPTECs lacking ATR also have increased expression of genes encoding CTGF, TGF- $\beta$, COL1 $\alpha 1$, and fibronectin, which likely reflects the senescence-associated prosecretory phenotype (SASP), a characteristic of cellular senescence(67).

Atr deletion after birth leads to premature aging and spontaneous fibrosis in multiple organs in mice (19). In humans, recessive mutation of FANCD2/FANCI-associated nuclease 1 (FAN1, a major component of DDR signaling) results in chronic interstitial nephropathy $(68,69)$. Furthermore, in experimental models, global deletion of the component of the DDR protein ATM or FAN1 resulted in increased DNA damage and/or organ injury and fibrosis in heart and liver $(60,68-72)$. As such, we designed our experiments to specifically explore the role of ATR in PT injury, avoiding the global effects of loss of ATR activity. Furthermore, we sought to avoid any effects of long-term ATR knockout by inducing deletion of the Atr gene shortly before injury. In many forms of human kidney injury, as well as in animal models, RPTECs are the cell type that sustains the most injury, including DNA damage. Although it remains possible that loss of ATR in other tubule segments might further worsen the injury, these effects will likely be limited in the IRI and cisplatin models, since the majority of the DNA damage occurred in the PT in the models tested.

In 2011, Narita et al. demonstrated that senescent cells formed a structure in the cytosol consisting of components of the mTOR and autophagy pathways, which are normally counter-regulatory (51). These TASCCs were found to be unique in senescent cells and critical for the enhanced secretion found in these cells (51). Recently, we demonstrated that TASCC formation is a critical step in the AKI-to-CKD transition (25). Inhibition of RAPTOR, a necessary factor for TASCC formation 3 weeks after injury, was sufficient to prevent TASCC formation and fibrosis (25). Here, we demonstrate for the first time to our knowledge that TASCCs are present in injured PT-like cells in human kidney organoids. We also found that $\mathrm{ATR}^{\mathrm{RPTC} /-}$ mice had increased numbers of TASCCs following injury, which correlated with increased fibrosis in these mice. These data suggest that TASCC formation serves as a mechanistic link of RPTEC-reduced ATR activity and fibrosis. This probably occurs through upregulation of the p53/p21 pathway, which we have shown induces TASCCs through the $G_{2} / M$ arrest inducer cyclin $G_{1}(25)$.

In addition to understanding the role of the DDR in regulating kidney injury and repair, a better understanding of this pathway will be particularly relevant to therapeutic approaches directed toward malignancy. Inhibitors of molecules involved in DNA repair and the cell cycle, such as ATM, ATR, CHK1, and WEE1, are being tested as cancer therapeutics (73). Cancer cells are known to rely on cell-cycle and DNA damage checkpoints to counteract replication stress (74). DDR inhibitors act by releasing these checkpoints and driving the cells toward cell death. These DDR inhibitors are often given in combination with known nephrotoxic drugs, such as cisplatin, and our data indicated that these anti-ATR therapeutics could have unintended side effects that increase injury to the kidney, especially in the setting of wellknown nephrotoxicants (75).

Given our results, it is important to recognize that anti-ATRdirected therapies may lead to chronic fibrotic damage in the kidney and potentially other organs. The clinicaltrials.gov global database shows 12 registered ongoing ATR inhibitor studies, used either as single agents or in combination with cisplatin and other chemotherapeutic compounds (75). Previously, our laboratory demonstrated that repetition of mild renal impairment causes CKD (8). Since ATR inhibition may amplify otherwise minor endogenous or exogenous stresses to the kidney, our results indicate that patients treated with these ATR inhibitors may develop adverse kidney consequences.

In conclusion, we have demonstrated that RPTEC ATR, a sensor of DNA damage, is crucial for adaptive repair and that, in its absence, there is enhanced maladaptive kidney repair with an increased number of senescent cells in the $G_{2} / M$ phase of the cell cycle and an increased profibrotic secretory phenotype with consequent development of kidney tissue fibrosis. 
A LC3/mTOR/DAPI
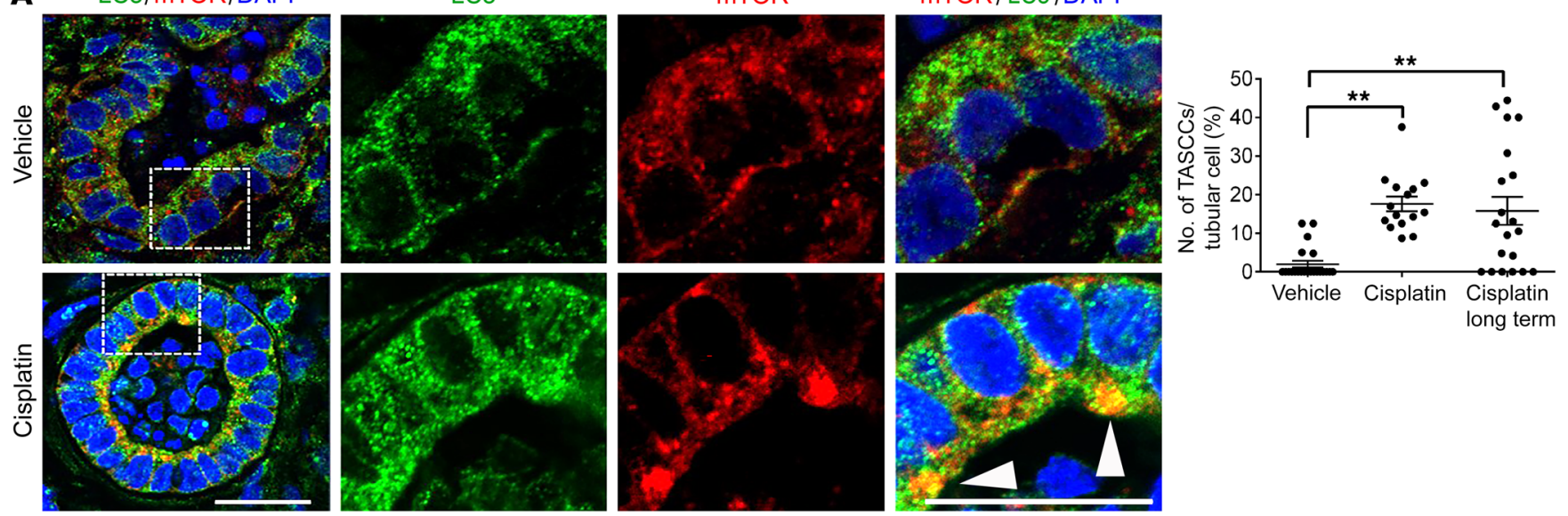

B UUO

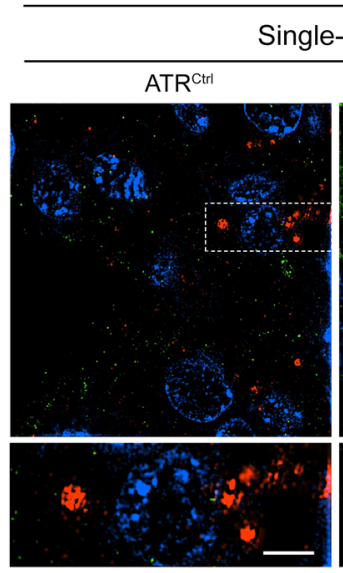

-plane image

ATR RPTC-1-
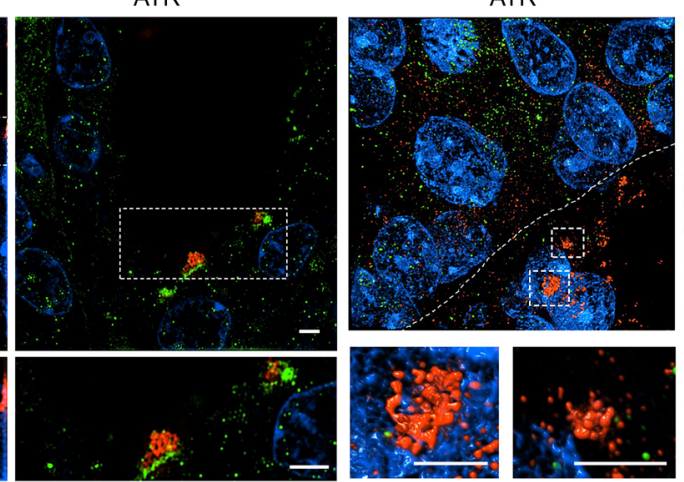

LC3/mTOR/DAP

mTOR/LC3/DAPI

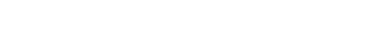


Kidney organoid IF analysis. Cryosections of 10- $\mu \mathrm{m}$ thickness were mounted onto Denville white-frosted, positively charged (Denville) microscope slides, air dried, and treated for IF analysis as described previously (79). Primary antibodies against the following proteins were used: ATR (goat polyclonal, 1:100, catalog sc1887, Santa Cruz Biotechnology); pATR (Ser428) (rabbit polyclonal, 1:100, catalog 2853, Cell Signaling Technology); pH3 (rabbit, 1:100, catalog 06-570, MilliporeSigma); H2AX (Ser139) ( $\gamma \mathrm{H} 2 \mathrm{AX}$ ) (mouse monoclonal, 1:250 catalog 05-636, MilliporeSigma); Ki67 (Abcam ab15580); mTOR (7C10, Cell Signaling Technology); and LC3 (Nanotools, 5F10). Staining of biotinylated lotus lectin (1:200, catalog B-1325, Vector Laboratories) required the use of a Streptavidin/Biotin Blocking Kit (Vector Laboratories, SP-2002). FITC-, Cy3-, or Cy5-conjugated secondary antibodies (Life Technologies, Thermo Fisher Scientific) were used according to the manufacturer's instructions. Nuclei were counterstained using VECTASHIELD with DAPI (catalog H-1200, Vector Laboratories). Images were obtained by confocal microscopy (Nikon C1 Eclipse, Nikon).

Kidney organoid experiment with cisplatin and VE-821. Kidney organoids on day 64 were treated with $10 \mu \mathrm{M}$ VE-821 or control DMSO in advanced RPMI for 6 hours (pretreatment). A 5- $\mu \mathrm{M}$ final concentration of cisplatin or control saline was added to the media. After 24 hours of exposure to cisplatin, media were replaced with new advanced RPMI. Twenty-four hours after changing media or 120 hours later (long term), the organoids were fixed and prepared as described above.

Genetically modified mice. To inactivate Atr in a tissue-specific fashion, mice carrying the PT-specific promotor Slc34a1 driving the eGFPCreERT ${ }^{2}$ fusion protein (Slc34a1 ${ }^{G C E}$ ) (The Jackson Laboratory; originally from Benjamin Humphreys, Washington University, St. Louis, Missouri, USA)(39) were crossed with mice carrying only 1 normal Atr allele (Atr ${ }^{+-}$mice). The use of Atr-floxed/-null alleles has previously been shown to enhance the phenotype of Atr tissue-specific knockouts (19). The Atr ${ }^{+/-}$Slc34a1 ${ }^{\text {GCE } /+}$ progeny were mated with $A t r^{f / / f l}$ mice to generate $A t r r^{f /-} S l c 34 a 1^{G C E /+}$ mice. Atr $r^{f /-} S l c 34 a 1^{G C E}$ mice were crossed to produce Atr ${ }^{f /-}$ Slc34a $1^{G C E /+}$ and $A t r^{f / f l} S l c 34 a 1^{G C E /+}$ mice, which were used for experiments (ATR ${ }^{\mathrm{RPTC}-/}$ ). Mice carrying the floxed allele but lacking Cre, Atr ${ }^{f / f l} S l c 34 a 1^{G C E /-}$, or $A t r^{f l /-} S l c 34 a 1^{G C E /-}$ were used as controls (ATR $\left.{ }^{\mathrm{Ctrl}}\right)$. The $\mathrm{Atr}^{+/-}$and $A \operatorname{tr}^{\mathrm{fl} / \mathrm{fl}}$ mice were provided by Eric J. Brown (Perelman School of Medicine, University of Pennsylvania, Philadelphia, Pennsylvania, USA).

Animal experiments. To upregulate Slc34a1 ${ }^{G C E}$ expression, mice were fed a low-phosphorus (0.06\%) diet (TestDiet) (39). For Atr deletion in RPTECs, adult mice (8-10 weeks of age) were i.p. administered every other day 3 doses (3-mg) of tamoxifen (MilliporeSigma) dissolved in 3\% (vol/vol) ethanol-containing corn oil (MilliporeSigma), and cisplatin was injected 1 week after the last dose. For IRI and UUO, the mice were treated with 3 doses of tamoxifen by oral gavage $(10 \mathrm{mg}$ every other day), and surgery was performed 1 week after the last dose. In all cases, littermate control phenotypes were compared.

IRI. Ischemia for 28 minutes at $37^{\circ} \mathrm{C}$ was induced in both kidneys using a bilateral flank approach as previously reported (80). Warm saline $\left(1 \mathrm{~mL}\right.$ at $\left.37^{\circ} \mathrm{C}\right)$ was injected i.p. after surgery for volume supplementation. The technical success of ischemia-reperfusion was monitored by checking the kidney color after clamping and after removing the clamps. Sham operations were performed with exposure of both kidneys, but without induction of ischemia.
Cisplatin administration to mice. Mice were administered cisplatin (MilliporeSigma; $1 \mathrm{mg} / \mathrm{mL}$ solution in sterile normal saline) or vehicle (normal saline) at $20 \mathrm{mg} / \mathrm{kg}$ in a single i.p. injection. Mice were sacrificed 96 hours after administration of cisplatin, and tissue and blood were collected for further analysis.

UUO. Mice were anesthetized and the left kidney exposed by flank incision. The ureter was ligated with 6-0 silk at 2 points, close to the renal pelvis (81).

Renal function. Serum creatinine was measured with a Beckman Creatinine Analyzer 2 using the Jaffe rate method. Serum BUN was measured using the Infinity Urea Kit (Thermo Fisher Scientific).

SIM. Paraffin-embedded tissue was sectioned at 4- to $6-\mu \mathrm{m}$ thickness and mounted onto (3-aminopropyl) trimethoxysilane-treated coverslips (mounting the tissue to the coverslip is necessary, as super-resolution microscopes have limited working distances). Antigen retrieval was performed by incubating the sections under high temperature $\left(120^{\circ} \mathrm{C}\right)$ and high pressure in citrate buffer using a pressure cooker. Sections were then blocked with BSA and normal donkey serum, followed by staining with anti-mTOR (Cell Signaling Technology, 7C10) and/or anti-LC3 (Nanotools, 5F10) antibodies and the corresponding secondary antibodies (Jackson Immunoresearch). Tissue sections were imaged on a Nikon structured illumination microscope (N-SIM) as a $Z$-stack at $0.12-\mu \mathrm{m}$ thickness using a $\times 100$ TIRF objective. The resulting $Z$-stack was rendered in 3D in NISElements (Nikon) for image analysis. The movie was generated with Imaris software (Bitplane). SIM imaging was performed at the Nikon Center of Excellence at Vanderbilt University and the Vanderbilt Cell Imaging Shared Resource.

Primary RPTECs from FUCCI ${ }^{+}$mice. FUCCI is a technology that visualizes the cell cycle by labeling distinct fluorescence - KusabiraOrange 2 in the $G_{1}$ phase and Azami-Green1 during the $S / G_{2} / M$ phase - which allows for determination of $G_{1}$, early $S$, and $S / G_{2} / M$ phases of the cell cycle. To generate RPTEC-specific FUCCI ${ }^{+}$mice, we crossed B6;129-Gt (ROSA)26Sor $<\mathrm{tm} 1$ (Fucci2aR) Jkn> mice (provided by Ian Jackson, University of Edinburgh, Edinburgh, United Kingdom) with $\gamma$ GT-Cre mice [obtained from The Jackson Laboratory, stock $\operatorname{Tg}$ (Ggt1-cre)M3Egn/J]. RPTECs were harvested from the mice as described previously (82). Briefly, kidney cortex was minced into small pieces, incubated with collagenase $(1 \mathrm{mg} / \mathrm{mL})$ and trypsin inhibitor $(1 \mathrm{mg} / \mathrm{mL})$ in oxygenated media at $37^{\circ} \mathrm{C}$ with vigorous shaking, and then centrifuged in $32 \%$ Percoll and diluted in DMEM/F-12 to isolate RPTECs from other fractions. These isolated tubules were plated on collagen-coated dishes and then maintained in RPTEC media (DMEM/F-12 medium supplemented with $5 \mu \mathrm{g} / \mathrm{mL}$ transferrin, $5 \mu \mathrm{g} / \mathrm{mL}$ insulin, $0.05 \mu \mathrm{M}$ hydrocortisone, and $50 \mu \mathrm{M}$ vitamin C). After expression of fluorescence was confirmed, isolated RPTECs were synchronized by incubation in RPTEC media containing 1\% FBS. Cells were pretreated or not with VE-821 $(10 \mu \mathrm{M})$ for 2 hours and then incubated with PBS or cisplatin $(0.1 \mu \mathrm{g} / \mathrm{mL})$ in the presence or absence of VE-821 $(10 \mu \mathrm{M})$. After a 48-hour exposure to cisplatin, FUCCI RPTECs were harvested with $0.25 \%$ trypsin and $2.21 \mathrm{mM}$ EDTA (Corning, 25-053-Cl), fixed with BD Cytofix/Cytoperm (BD, catalog $554714)$, and stained with DAPI at a concentration of $1 \mu \mathrm{g} / \mathrm{mL}$. The cell cycle was examined by flow cytometry using a 4-laser LSRFortessa (BD) and analyzed with FlowJo software (BD).

In vitro FUCCI cell analysis. HK2 (American Type Culture Collection [ATCC]) cells expressing FUCCI (47) were obtained by suc- 
cessive transduction with lentiviral vectors expressing mKO-Cdt1 and mAG-geminin, respectively. Cells were imaged using a Nikon TE2000-S live microscope at $37^{\circ} \mathrm{C}$ in an ambient atmosphere in phenol red-free L15 Leibovitz's medium supplemented with 10\% FBS. Pifithrin- $\alpha$ (Selleckchem, S2929) was used at $50 \mathrm{nM}$ for p53 inhibition and the PLK1 inhibitor rigosertib (Selleckchem, S1362) at $10 \mathrm{nM}$ for induction of $\mathrm{G}_{2} / \mathrm{M}$ arrest. Triple acquisition for bright-field, $\mathrm{mKO}$ (excitation 550/20, emission 585/20), and mAG (excitation 495/10, emission 540/40) was achieved every 30 minutes. Background subtraction and correction of the fluorescence spill from $\mathrm{mKO}$ in the $\mathrm{mAG}$ channel was performed using Fiji (83), and the fluorescence signals were then quantified for each individual cell in every field for every time point using the TrackMate plug-in (84). M-phase cells (defined by cytodieresis) were excluded from analysis.

Statistics. Statistical analyses were performed using GraphPad Prism 6.07 (GraphPad Software). All results are reported as the mean \pm SEM. Statistical significance was determined using a 2-tailed, unpaired $t$ test or 1-way ANOVA followed by Tukey's post hoc test. Survival curves were derived using the Kaplan-Meier method and compared using a log-rank test. Correlations were determined by Pearson's correlation analysis. A $P$ value of less than 0.05 was interpreted as statistically significant.

Study approval. The studies in animals were reviewed and approved by the IACUC and the Harvard Medical Area Standing Committee on Animals (protocol 03602). Human studies were approved by the IRB of the Ethics Committee of Tokushima University Hospital in Tokushima, Japan (protocol 680). All patients provided written informed consent.

\section{Author contributions}

The order of the co-first authors, SK and CRB, was determined on the basis of when they began work on the study (SK started the study and CRB joined the project later). JVB formulated and conceived of this study. SK, CRB, LG, TI, RM, and JVB designed experiments. SK performed experiments. CRB, KT, PG, YM, BCE, TI, RM, NG, TS, and QW perform experiments. SK, TI, QW, and TS maintained animals. RM maintained hPSCs and generated kidney organoids. YM and NG performed organoid experiments.
SK, CRB, TI, AA, RM, NG, and JVB analyzed the data. SK, CRB, RM, NG, and JVB wrote the manuscript. All authors helped to interpret results and approved the final version of the manuscript.

\section{Acknowledgments}

We thank Hiroshi Itoh and Toshiaki Monkawa (Keio University School of Medicine, Tokyo, Japan) for the mouse anti-KSP antibody and Lorraine Racusen (Johns Hopkins Hospital, Baltimore, Maryland, USA) for the HKC-8 cells. This work was supported by grants from the National Institute of Diabetes and Digestive and Kidney Diseases (NIDDK), NIH (R37 DK39773, RO1 DK072381, and UG TR002155, to JVB); a Grant-in-Aid for Scientific Research (C, 16K09620); a Research Fellowship from the Sumitomo Life Welfare and Culture Foundation (to SK); a NIH T32 Fellowship Training Grant (DK007527, to NG); a Harvard Stem Cell Institute (HSCI) Cross-Disciplinary Fellowship Grant (to NG); a Brigham and Women's Hospital Research Excellence Award (to NG and $\mathrm{RM}$ ); the Novartis Foundation for Gerontological Research (to $\mathrm{SK})$; the Uehara Memorial Foundation (to RM); a Grant-in-Aid from the Japan Society for the Promotion of Science (JSPS) Postdoctoral Fellowship for Research Abroad (to RM); a Brigham and Women's Hospital Faculty Career Development Award (to RM); a Harvard Stem Cell Institute Seed Grant (to RM); Ajinomoto Co. Inc. (to RM); the DiaComp Pilot and Feasibility Program (to RM); and the NIDDK, NIH (R01 DK121101, K01DK099473, and P30 DK114809, to CRB). PG is supported by a grant from the ATIP Avenir program (INSERM-CNRS). SIM imaging was performed at the Nikon Center of Excellence at Vanderbilt University and the Vanderbilt Cell Imaging Shared Resource (supported by NIH grants CA68485, DK20593, DK58404, DK59637, and EY08126).

Address correspondence to: Craig R. Brooks, MCN Room S-3223B, 1161 21st Avenue South, Nashville, Tennessee 37232, USA. Phone: 615.343.3868; Email: craig.brooks@vanderbilt.edu. Or to: Joseph V. Bonventre, Harvard Institutes of Medicine Room 570, 4 Blackfan Circle, Boston, Massachusetts 02115, USA. Phone: 617.525.5960; Email: joseph_bonventre@hms.harvard.edu.
1. Chertow GM, Burdick E, Honour M, Bonventre JV, Bates DW. Acute kidney injury, mortality, length of stay, and costs in hospitalized patients. J Am Soc Nephrol. 2005;16(11):3365-3370.

2. Bonventre JV, Yang L. Cellular pathophysiology of ischemic acute kidney injury. JClin Invest. 2011;121(11):4210-4221.

3. Palomba H, Castro I, Yu L, Burdmann EA. The duration of acute kidney injury after cardiac surgery increases the risk of long-term chronic kidney disease. J Nephrol. 2017;30(4):567-572.

4. [No authors listed]. Chronic kidney disease fact sheet. World Kidney Day. https://www. worldkidneyday.org/facts/chronic-kidneydisease/. Accessed August 14, 2019.

5. Ferenbach DA, Bonventre JV. Acute kidney injury and chronic kidney disease: From the laboratory to the clinic. Nephrol Ther. 2016;12(Suppl 1):S41-S48.

6. Zuk A, Bonventre JV. Acute kidney injury. Annu Rev Med. 2016;67:293-307.

7. Yang L, Besschetnova TY, Brooks CR, Shah JV, Bonventre JV. Epithelial cell cycle arrest in G2/M mediates kidney fibrosis after injury. Nat Med. 2010;16(5):535-543.

8. Grgic I, et al. Targeted proximal tubule injury triggers interstitial fibrosis and glomerulosclerosis. Kidney Int. 2012;82(2):172-183.

9. Ma Z, Wei Q, Dong G, Huo Y, Dong Z. DNA damage response in renal ischemia-reperfusion and ATP-depletion injury of renal tubular cells. Biochim Biophys Acta. 2014;1842(7):1088-1096.

10. Pabla N, Huang S, Mi QS, Daniel R, Dong Z. ATRChk2 signaling in $\mathrm{p} 53$ activation and DNA damage response during cisplatin-induced apoptosis. J Biol Chem. 2008;283(10):6572-6583.

11. Zhu S, Pabla N, Tang C, He L, Dong Z. DNA damage response in cisplatin-induced nephrotoxicity. Arch Toxicol. 2015;89(12):2197-2205.

12. Pressly JD, Park F. DNA repair in ischemic acute kidney injury. Am J Physiol Renal Physiol. 2017;312(4):F551-F555.

13. Li Z, Pearlman AH, Hsieh P. DNA mismatch repair and the DNA damage response. DNA Repair (Amst). 2016;38:94-101.
14. Awasthi P, Foiani M, Kumar A. ATM and ATR signaling at a glance. J Cell Sci. 2015;128(23):4255-4262.

15. Brown EJ, Baltimore D. Essential and dispensable roles of ATR in cell cycle arrest and genome maintenance. Genes Dev. 2003;17(5):615-628.

16. Kidiyoor GR, Kumar A, Foiani M. ATR-mediated regulation of nuclear and cellular plasticity. DNA Repair (Amst). 2016;44:143-150.

17. O'Driscoll M, Ruiz-Perez VL, Woods CG, Jeggo PA, Goodship JA. A splicing mutation affecting expression of ataxia-telangiectasia and Rad3related protein (ATR) results in Seckel syndrome. Nat Genet. 2003;33(4):497-501.

18. Sancar A, Lindsey-Boltz LA, Unsal-Kaçmaz K, Linn S. Molecular mechanisms of mammalian DNA repair and the DNA damage checkpoints. Annu Rev Biochem. 2004;73:39-85.

19. Ruzankina Y, et al. Deletion of the developmentally essential gene ATR in adult mice leads to age-related phenotypes and stem cell loss. Cell Stem Cell. 2007;1(1):113-126. 
20. Murga M, et al. A mouse model of ATR-Seckel shows embryonic replicative stress and accelerated aging. Nat Genet. 2009;41(8):891-898.

21. McKinnon PJ. DNA repair deficiency and neurological disease. Nat Rev Neurosci. 2009;10(2):100-112.

22. Humphreys BD, et al. Fate tracing reveals the pericyte and not epithelial origin of myofibroblasts in kidney fibrosis. Am J Pathol. 2010;176(1):85-97.

23. Humphreys BD, Czerniak S, DiRocco DP, Hasnain W, Cheema R, Bonventre JV. Repair of injured proximal tubule does not involve specialized progenitors. Proc Natl Acad Sci USA. 2011;108(22):9226-9231.

24. Ichimura T, Asseldonk EJ, Humphreys BD, Gunaratnam L, Duffield JS, Bonventre JV. Kidney injury molecule- 1 is a phosphatidylserine receptor that confers a phagocytic phenotype on epithelial cells. J Clin Invest. 2008;118(5):1657-1668.

25. Canaud G, et al. Cyclin G1 and TASCC regulate kidney epithelial cell $\mathrm{G}_{2}-\mathrm{M}$ arrest and fibrotic maladaptive repair. Sci Transl Med. 2019;11(476):eaav4754.

26. Kuo LJ, Yang LX. Gamma-H2AX - a novel biomarker for DNA double-strand breaks. In Vivo. 2008;22(3):305-309.

27. Rogakou EP, Pilch DR, Orr AH, Ivanova VS, Bonner WM. DNA double-stranded breaks induce histone H2AX phosphorylation on serine 139. J Biol Chem. 1998;273(10):5858-5868.

28. Rogakou EP, Boon C, Redon C, Bonner WM. Megabase chromatin domains involved in DNA double-strand breaks in vivo. J Cell Biol. 1999;146(5):905-916.

29. Hasty P, Campisi J, Hoeijmakers J, van Steeg H, Vijg $\mathrm{J}$. Aging and genome maintenance: lessons from the mouse? Science. 2003;299(5611):1355-1359.

30. Siddik ZH. Cisplatin: mode of cytotoxic action and molecular basis of resistance. Oncogene. 2003;22(47):7265-7279.

31. Boeckman HJ, Trego KS, Turchi JJ. Cisplatin sensitizes cancer cells to ionizing radiation via inhibition of nonhomologous end joining. Mol Cancer Res. 2005;3(5):277-285.

32. Schrier RW. Cancer therapy and renal injury. JClin Invest. 2002;110(6):743-745.

33. Megyesi J, Safirstein RL, Price PM. Induction of p21WAF1/CIP1/SDI1 in kidney tubule cells affects the course of cisplatin-induced acute renal failure. J Clin Invest. 1998;101(4):777-782.

34. Ramesh G, Reeves WB. TNF-alpha mediates chemokine and cytokine expression and renal injury in cisplatin nephrotoxicity. JClin Invest. 2002;110(6):835-842.

35. Sánchez-González PD, López-Hernández FJ, López-Novoa JM, Morales AI. An integrative view of the pathophysiological events leading to cisplatin nephrotoxicity. Crit Rev Toxicol. 2011;41(10):803-821.

36. Miller RP, Tadagavadi RK, Ramesh G, Reeves WB. Mechanisms of cisplatin nephrotoxicity. Toxins (Basel). 2010;2(11):2490-2518.

37. Morizane R, Lam AQ, Freedman BS, Kishi S, Valerius MT, Bonventre JV. Nephron organoids derived from human pluripotent stem cells model kidney development and injury. Nat Biotechnol. 2015;33(11):1193-1200.
38. Morizane R, Bonventre JV. Generation of nephron progenitor cells and kidney organoids from human pluripotent stem cells. Nat Protoc. 2017;12(1):195-207.

39. Kusaba T, Lalli M, Kramann R, Kobayashi A, Humphreys BD. Differentiated kidney epithelial cells repair injured proximal tubule. Proc Natl Acad Sci USA. 2014;111(4):1527-1532.

40. Morizane R, et al. miR-34c attenuates epithelialmesenchymal transition and kidney fibrosis with ureteral obstruction. Sci Rep. 2014;4:4578.

41. Kishi S, et al. Meclizine preconditioning protects the kidney against ischemia-reperfusion injury. EBioMedicine. 2015;2(9):1090-1101.

42. Morizane R, et al. Kidney specific protein-positive cells derived from embryonic stem cells reproduce tubular structures in vitro and differentiate into renal tubular cells. PLOS ONE. 2014;8(6):e64843.

43. Zhang $\mathrm{P}$, et al. Renal medulla is more sensitive to cisplatin than cortex revealed by untargeted mass spectrometry-based metabolomics in rats. Sci Rep. 2017;7:44804.

44. Zou L, Elledge SJ. Sensing DNA damage through ATRIP recognition of RPA-ssDNA complexes. Science. 2003;300(5625):1542-1548.

45. Lu C, et al. Cell apoptosis: requirement of $\mathrm{H} 2 \mathrm{AX}$ in DNA ladder formation, but not for the activation of caspase-3. Mol Cell. 2006;23(1):121-132.

46. Cook PJ, Ju BG, Telese F, Wang X, Glass CK, Rosenfeld MG. Tyrosine dephosphorylation of H2AX modulates apoptosis and survival decisions. Nature. 2009;458(7238):591-596.

47. Sakaue-Sawano A, et al. Visualizing spatiotemporal dynamics of multicellular cell-cycle progression. Cell. 2008;132(3):487-498.

48. Enriquez-Rios V, et al. DNA-PKcs, ATM, and ATR Interplay Maintains Genome Integrity during Neurogenesis. J Neurosci. 2017;37(4):893-905.

49. Forbes MS, Thornhill BA, Minor JJ, Gordon KA Galarreta CI, Chevalier RL. Fight-or-flight: murine unilateral ureteral obstruction causes extensive proximal tubular degeneration, collecting duct dilatation, and minimal fibrosis. Am J Physiol Renal Physiol. 2012;303(1):F120-F129.

50 . Brahmer J, et al. Nivolumab versus docetaxel in advanced squamous-cell non-small-cell lung cancer. N Engl J Med. 2015;373(2):123-135.

51. Narita M, et al. Spatial coupling of mTOR and autophagy augments secretory phenotypes. Science. 2011;332(6032):966-970.

52. Lan R, et al. PTEN loss defines a TGF- $\beta$-induced tubule phenotype of failed differentiation and JNK signaling during renal fibrosis. Am J Physiol Renal Physiol. 2012;302(9):F1210-F1223.

53. Canaud G, Bonventre JV. Cell cycle arrest and the evolution of chronic kidney disease from acute kidney injury. Nephrol Dial Transplant. 2015;30(4):575-583.

54. Maréchal A, Zou L. DNA damage sensing by the ATM and ATR kinases. Cold Spring Harb Perspect Biol. 2013;5(9):a012716.

55.Jiang M, Yi X, Wang C-Y, Dong Z. Role of p53 in cisplatin-induced tubular cell apoptosis: dependence on p53 transcriptional activity. Am J Physiol Renal Physiol. 2004;287(6):F1140-7.

56. Brown EJ, Baltimore D. ATR disruption leads to chromosomal fragmentation and early embryon- ic lethality. Genes Dev. 2000;14(4):397-402.

57. Roos WP, Thomas AD, Kaina B. DNA damage and the balance between survival and death in cancer biology. Nat Rev Cancer. 2016;16(1):20-33.

58. Manolopoulou M, et al. Novel kidney dissociation protocol and image-based flow cytometry facilitate improved analysis of injured proximal tubules. Am J Physiol Renal Physiol. 2019;316(5):F847-F855.

59. Jackson SP, Bartek J. The DNA-damage response in human biology and disease. Nature. 2009;461(7267):1071-1078.

60. Daniel LL, Daniels CR, Harirforoosh S, Foster CR, Singh M, Singh K. Deficiency of ataxia telangiectasia mutated kinase delays inflammatory response in the heart following myocardial infarction. J Am Heart Assoc. 2014;3(6):e001286.

61. Kipling D, Davis T, Ostler EL, Faragher RG. What can progeroid syndromes tell us about human aging? Science. 2004;305(5689):1426-1431.

62. Ferenbach DA, Bonventre JV. Mechanisms of maladaptive repair after AKI leading to accelerated kidney ageing and CKD. Nat Rev Nephrol. 2015;11(5):264-276.

63. Branzei D, Foiani M. Regulation of DNA repair throughout the cell cycle. Nat Rev Mol Cell Biol. 2008;9(4):297-308.

64. Phillippe M, Phillippe SM. Birth and death: evidence for the same biologic clock. Am J Reprod Immunol. 2017;77(5):264-276.

65. Ishikawa N, et al. Changes of telomere status with aging: An update. Geriatr Gerontol Int. 2016;16(Suppl 1):30-42.

66. Burtner CR, Kennedy BK. Progeria syndromes and ageing: what is the connection? Nat Rev Mol Cell Biol. 2010;11(8):567-578.

67. Young AR, Narita M. SASP reflects senescence. EMBO Rep. 2009;10(3):228-230.

68. Airik R, et al. A FANCD2/FANCI-associated nuclease 1-knockout model develops karyomegalic interstitial nephritis. J Am Soc Nephrol. 2016;27(12):3552-3559.

69. Zhou W, et al. FAN1 mutations cause karyomegalic interstitial nephritis, linking chronic kidney failure to defective DNA damage repair. Nat Genet. 2012;44(8):910-915.

70. Foster CR, Daniel LL, Daniels CR, Dalal S, Singh M, Singh K. Deficiency of ataxia telangiectasia mutated kinase modulates cardiac remodeling following myocardial infarction: involvement in fibrosis and apoptosis. PLoS One. 2013;8(12):e83513.

71. Lu S, Shen KC, Wang Y, Brooks SC, Wang YA. Impaired hepatocyte survival and liver regeneration in Atm-deficient mice. Hum Mol Genet. 2005;14(20):3019-3025.

72. Foster CR, Zha Q, Daniel LL, Singh M, Singh K. Lack of ataxia telangiectasia mutated kinase induces structural and functional changes in the heart: role in $\beta$-adrenergic receptor-stimulated apoptosis. Exp Physiol. 2012;97(4):506-515.

73. Ronco C, Martin AR, Demange L, Benhida R. ATM, ATR, CHK1, CHK2 and WEE1 inhibitors in cancer and cancer stem cells. Medchemcomm. 2017;8(2):295-319.

74. Jackson SP, Helleday T. DNA Repair. Drugging DNA repair. Science. 2016;352(6290):1178-1179.

75. Rundle S, Bradbury A, Drew Y, Curtin NJ. Targeting the ATR-CHK1 axis in cancer therapy. 
Cancers (Basel). 2017;9(5):E41.

76. Matsuo S, et al. Revised equations for estimated GFR from serum creatinine in Japan. Am J Kidney Dis. 2009;53(6):982-992.

77. Morizane R, Bonventre JV. Kidney organoids: a translational journey. Trends Mol Med. 2017;23(3):246-263.

78. Morizane R, Miyoshi T, Bonventre JV. Concise review: kidney generation with human pluripotent stem cells. Stem Cells. 2017;35(11):2209-2217.

79. Ichimura T, et al. Kidney injury molecule-1 (KIM-1), a putative epithelial cell adhesion molecule containing a novel immunoglobulin domain, is up-regulated in renal cells after injury. J Biol Chem. 1998;273(7):4135-4142.

80. Park KM, Byun JY, Kramers C, Kim JI, Huang PL, Bonventre JV. Inducible nitric-oxide synthase is an important contributor to prolonged protective effects of ischemic preconditioning in the mouse kidney. J Biol Chem. 2003;278(29):27256-27266.

81. Humphreys BD, et al. Chronic epithelial kidney injury molecule-1 expression causes murine kid- ney fibrosis. JClin Invest. 2013;123(9):4023-4035. 82. Brooks C, Wei Q, Cho SG, Dong Z. Regulation of mitochondrial dynamics in acute kidney injury in cell culture and rodent models. J Clin Invest. 2009;119(5):1275-1285.

83. Schindelin J, et al. Fiji: an open-source platform for biological-image analysis. Nat Methods. 2012;9(7):676-682.

84. Tinevez JY, et al. TrackMate: An open and extensible platform for single-particle tracking. Methods. 2017;115:80-90. 